Published in final edited form as:

J Am Chem Soc. 2017 March 15; 139(10): 3805-3821. doi:10.1021/jacs.6b13384.

\title{
Structural, Kinetic, and Computational Characterization of the Elusive Arylpalladium(II)boronate Complexes in the Suzuki- Miyaura Reaction
}

\author{
Andy A. Thomas, Hao Wang, Andrew F. Zahrt, Scott E. Denmark \\ Roger Adams Laboratory, Department of Chemistry, University of Illinois, Urbana, Illinois 61801, \\ United States
}

\begin{abstract}
The existence of the oft-invoked intermediates containing the crucial $\mathrm{Pd}-\mathrm{O}-\mathrm{B}$ subunit, the "missing link", has been established in the Suzuki-Miyaura cross-coupling reaction. The use of low-temperature, rapid injection NMR spectroscopy (RI-NMR), kinetic studies, and computational analysis has enabled the generation, observation, and characterization of these highly elusive species. The ability to confirm the intermediacy of $\mathrm{Pd}-\mathrm{O}-\mathrm{B}$-containing species provided the opportunity to clarify mechanistic aspects of the transfer of the organic moiety from boron to palladium in the key transmetalation step. Specifically, these studies establish the identity of two different intermediates containing $\mathrm{Pd}-\mathrm{O}-\mathrm{B}$ linkages, a tri-coordinate (6-B-3) boronic acid complex and a tetra-coordinate (8-B-4) boronate complex, both of which undergo transmetalation leading to the cross-coupling product. Two distinct mechanistic pathways have been elucidated for stoichiometric reactions of these complexes: (1) transmetalation via an unactivated 6-B-3 intermediate that dominates in the presence of an excess of ligand, and (2) transmetalation via an activated 8-B-4 intermediate that takes place with a deficiency of ligand.
\end{abstract}

\section{Graphical Abstract}

\footnotetext{
*Corresponding Author: sdenmark@illinois.edu.

The authors declare no competing financial interest.

ASSOCIATED CONTENT

Supporting Information

The Supporting Information is available free of charge on the ACS Publications website at DOI: 10.1021/jacs.6b13384.

Full experimental procedures and characterization data and copies of ${ }^{1} \mathrm{H},{ }^{13} \mathrm{C},{ }^{31} \mathrm{P},{ }^{19} \mathrm{~F},{ }^{11} \mathrm{~B}$, NOESY, and EXSY spectra, along with full kinetic data (PDF)
} 


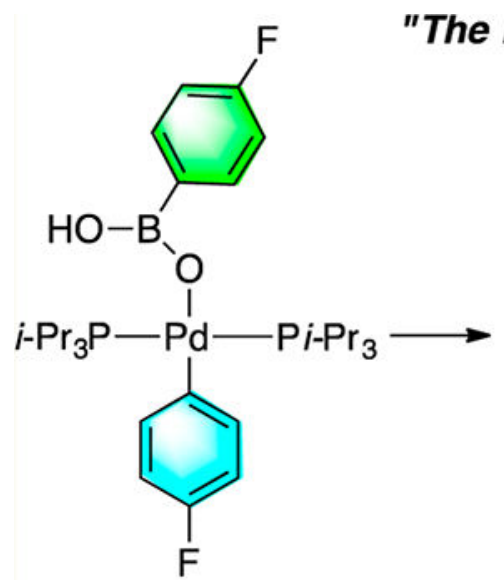

6-B-3

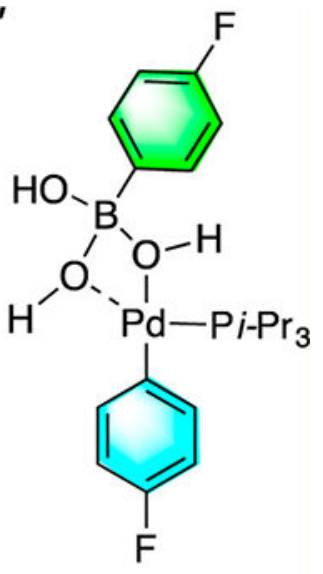

8-B-4

\section{INTRODUCTION}

Palladium-catalyzed cross-coupling reactions such as the Kumada-Tamao-Corriu ${ }^{1}(\mathrm{Mg})$, Suzuki-Miyaura $^{2}$ (B), Stille-Migita-Kosugi ${ }^{3}$ (Sn), Hiyama-Denmark ${ }^{4}$ (Si), and Negishi ${ }^{5}$ $(\mathrm{Zn})$ reactions have fundamentally changed the practice of organic synthesis in both academic and industrial settings alike (Figure 1). ${ }^{6}$ Among these reactions, the Nobel Prizesharing Suzuki-Miyaura reaction is the premier cross-coupling process, utilized across all disciplines of chemistry as well as in the industrial synthesis of fine chemicals ${ }^{7}$ and pharmaceuticals ${ }^{8}$ owing to its demonstrated reliability, broad functional group compatibility, and access to a wide variety of commercially available boron-based reagents. At a fundamental level, all of these reactions share the same basic catalytic cycle, comprised of three elementary steps: oxidative addition, transmetalation, and reductive elimination. The oxidative addition and reductive elimination steps are common to all cross-coupling variants; however, because the organometallic donor is involved only in the transmetalation step, it is this event that preparatively and mechanistically differentiates all of these processes.

The desire to understand the relationship between chemical structure and reactivity has led to many mechanistic investigations of these elementary steps. Particularly, the oxidative addition $^{9}$ and reductive elimination ${ }^{10}$ steps have been extensively studied, and those insights are applicable to all of the cross-coupling reactions. However, except for the Stille ${ }^{11}$ and more recently the Hiyama-Denmark ${ }^{12}$ couplings, far less is known about the intricate details of the transmetalation step for these cross-coupling reactions.

The formation of transient, pre-transmetalation intermediates ( $\mathrm{Pd}-\mathrm{O}-\mathrm{M}$ linkages) on the borderline of existence makes their observation and especially isolation difficult in practice. As a result, reaction kinetics, supported by computational modeling, are often used to investigate the mechanism. Because assumptions must be made about the identity of such intermediates with these experimental methods, the characterization or isolation of a putative intermediate would provide compelling evidence for their existence. However, here again, model compounds must be kinetically validated to demonstrate that the intermediate species is truly on the proposed reaction pathway. 
Despite the ubiquitous practice of the Suzuki-Miyaura reaction, a fundamental understanding of the transfer of the organic fragment from boron to palladium remains elusive. Since the discovery of this reaction, two mechanistic pathways (Path A and Path B, Scheme 1) that differ in the role of hydroxide ion have been proposed to initiate the transmetalation event. If the "missing link" (intermediates such as iii) between the starting materials and products could be identified, it would provide an unprecedented opportunity to directly interrogate the transmetalation step. Specifically, it would provide insights into the structural features that influence the rate of transmetalation from boron to palladium, which is often the turnover-limiting step. ${ }^{13}$

Building upon our recent mechanistic investigations on the transmetalation step in palladium-catalyzed coupling of organosilanolate salts, ${ }^{12}$ a program of study was undertaken to structurally, kinetically, and computationally characterize arylpalladium(II) arylboronate complexes in the Suzuki-Miyaura reaction. If these intermediates could be prepared and characterized, then their kinetic competence could be established with various ligand systems, and the comparison of these rates of transmetalation could be used to improve reaction design, especially phosphine ligand selection, along with other critical parameters for this cross-coupling process.

\section{BACKGROUND}

\subsection{Pathways for Transmetalation.}

Currently, two alternative processes (Path A and Path B) have been proposed to initiate the transmetalation event which differ in the precise role of the hydroxide ion which is required for the reaction to proceed. ${ }^{14,15}$ Path A, the "boronate pathway", proceeds through saturation of the boron valence in $\mathbf{1}$ to yield a metal trihydroxyarylboronate salt $\mathbf{2}$, which then displaces halide from the oxidative addition product $\mathbf{3}$, generating species $\mathbf{4}$ containing the critical $\mathrm{Pd}-$ O-B linkage. Path B, the "oxo-palladium pathway", proceeds through displacement of halide from the oxidative addition product 3 by hydroxide, thus creating a palladium hydroxide complex $\mathbf{5}$, which then combines with the Lewis acidic arylboronic acid $\mathbf{1}$, forging the same pre-transmetalation intermediate 4 (Figure 2).

2.1.1. Early Experimental Evidence for the Transmetalation Event.-In 1979, Suzuki and Miyaura examined the formation of 1,3-dienes by cross-coupling reactions between alkenylboranes and bromoalkenes in the presence of $\left(\mathrm{Ph}_{3} \mathrm{P}\right)_{4} \mathrm{Pd}$ as the catalyst. ${ }^{16}$ They observed that alkenylboronate $\mathbf{6}$ and $(E)$ - $\beta$-bromostyrene $\mathbf{7}$ failed to react in the absence of alkoxide bases, presumably because of the poor transmetalation reactivity of a non-nucleophilic, tri-coordinate alkenylboronate. However, upon the addition of NaOEt (2.0 equiv), the cross-coupling process was activated, and product $\mathbf{8}$ was obtained in an $80 \%$ yield (Scheme 2). Initially the base was proposed to react with the Lewis acidic boron center to give a more nucleophilic boronate (Path A), ${ }^{17}$ which is then capable of transferring its organic group to palladium.

In 1985, Suzuki and Miyaura established that preformed alkoxy-palladium complex 9 reacted with alkenylboronate $\mathbf{1 0}$ to form 11, whereas chloropalladium complex $\mathbf{1 2}$ did not (Scheme 3). ${ }^{18}$ The suggestion that the base was capable of activating the palladium center 
prior to transmetalation (Path B) created a controversy that is still not fully settled. In any event, these studies did not provide unambiguous evidence for the intermediacy of species containing a discrete $\mathrm{Pd}-\mathrm{O}-\mathrm{B}$ linkage.

Preliminary evidence for the involvement of a $\mathrm{Pd}-\mathrm{O}-\mathrm{B}$ moiety was provided by an early investigation by Soderquist ${ }^{19}$ in which the diastereospecificity of the transmetalation step was examined. Subjecting both $\operatorname{syn}(\mathbf{1 3})$ and anti (14) deuterium-labeled isomers of $B-(3,3,-$ dimethyl-1,2-dideuterio-1-butyl)-9-BBN to standard Suzuki-Miyaura cross-coupling conditions (THF, $\mathrm{NaOH},\left(\mathrm{Ph}_{3} \mathrm{P}\right)_{4} \mathrm{Pd}$ ) led to complete retention of configuration in the coupling product (Scheme 4). Although no pre-transmetalation intermediate was observed, the retention of configuration indirectly establishes that a $\mathrm{Pd}-\mathrm{O}-\mathrm{B}$ linkage is involved in the transmetalation event.

2.1.2. Computational Studies.-Distinguishing the way in which $\mathrm{Pd}-\mathrm{O}-\mathrm{B}$ linkages are formed in the Suzuki-Miyaura reaction has proven to be challenging, as mechanistic studies are complicated by biphasic reaction conditions (e.g., THF and aqueous base) and by the poor solubility of inorganic bases and metal organoboronate salts in many organic solvents. Consequently, density functional theory (DFT) computational studies have provided insights that suggest Path $\mathrm{A}$ is responsible for the formation of pre-transmetalation intermediates. Interestingly, in $\mathrm{Ph}_{3} \mathrm{P}-$ ligated complexes, Maseras and Ujaque ${ }^{20}$ have calculated that the displacement of bromide from the oxidative addition product 18 with trihydroxyphenylboronate (2) was slightly lower $\left(\Delta \Delta G^{\dagger}=2.6 \mathrm{kcal} / \mathrm{mol}\right)$ in energy than the reaction of palladium hydroxide complex 19 with 1 , suggesting that both paths are capable of forming Pd-O-B linkages. However, the displacement of bromide with hydroxide from complex 18 was found to have a transition-state barrier of $18.6 \mathrm{kcal} / \mathrm{mol}$, which suggests that Path A is more favorable than Path B (Figure 3). ${ }^{21}$ Moreover, the impact of phosphine ligand on the transmetalation event has been computationally studied in depth by Lloyd-Jones and Harvey using $t-\mathrm{Bu}_{3} \mathrm{P},\left(\mathrm{CF}_{3}\right)_{3} \mathrm{P},\left(\mathrm{CH}_{3}\right)_{3} \mathrm{P}$, and $\mathrm{Ph}_{3} \mathrm{P}$. In this investigation, the steric parameters were found to be twice as important as the electronic parameters in the transmetalation event. $^{22}$

2.1.3. Experimental Studies.- - Understanding the role of hydroxide in the formation of the "missing link" iii (i.e., Path A or Path B) has inspired many investigations by Soderquist, ${ }^{19}$ Hartwig, ${ }^{23}$ Amatore and Jutand, ${ }^{24}$ and Schmidt. ${ }^{25}$ By performing stoichiometric reactions of preformed $\left(\mathrm{Ph}_{3} \mathrm{P}\right)_{2} \mathrm{PdPhBr}(\mathbf{1 8})$ and $\left(\mathrm{Ph}_{3} \mathrm{P}\right)_{2} \mathrm{PdPhOH}^{26}$ (19) with 22 and 21 respectively, Hartwig's group established that Path B is favored over Path A kinetically by more than 4 orders of magnitude (Scheme 5). Moreover, they established that the equilibrium population of 4-methylphenylboronic acid (21) and potassium 4methylphenyltrihydroxyboronate (22) in acetone $/ \mathrm{H}_{2} \mathrm{O}$ in the presence of 2.5 equiv of $\mathrm{K}_{2} \mathrm{CO}_{3}$ is ca. 1:1. Interestingly, the relative populations of trans- $\left(\mathrm{Cy}_{3} \mathrm{P}\right)_{2}\left(\mathrm{C}_{6} \mathrm{H}_{5}\right) \mathrm{Pd}(\mathrm{OH})(\mathbf{2 4})$ and trans- $\left(\mathrm{Cy}_{3} \mathrm{P}\right)_{2}\left(\mathrm{C}_{6} \mathrm{H}_{5}\right) \mathrm{Pd}(\mathrm{I})(\mathbf{5})$ are also approximately equal under simulated catalytic reaction conditions (Scheme 6). This conclusion was reinforced by extensive kinetic studies by Amatore and Jutand, who also identified multiple antagonistic roles for hydroxide ion. Although kinetic studies have provided evidence for these pathways, the actual composition and structure of the $\mathrm{Pd}-\mathrm{O}-\mathrm{B}$-containing species have not been determined. 
2.1.4. Attempts To Detect Reactive Intermediates.-To observe pretransmetalation intermediates, Canary and co-workers used electrospray mass spectrometry (ESI-MS) to probe the catalytic reaction between phenylboronic acid (1) and 3bromopyridine (27) in toluene using $\left(\mathrm{Ph}_{3} \mathrm{P}\right)_{4} \mathrm{Pd}$ and sodium carbonate as the base. ${ }^{27}$ During the course of these experiments, both $\left[(\mathrm{pyrH})(\mathrm{Br}) \mathrm{Pd}\left(\mathrm{Ph}_{3} \mathrm{P}\right)_{2}\right]^{+}(\mathbf{2 8})$ and $[(\mathrm{pyrH})-$ $\left.(\mathrm{Ph}) \mathrm{Pd}\left(\mathrm{Ph}_{3} \mathrm{P}\right)_{2}\right]^{+}(\mathbf{2 9})$ are detected. The observation of the oxidative addition intermediate 28 and transmetalation product $\mathbf{2 9}$ clearly demonstrates how difficult it is to investigate the transmetalation step of the catalytic process (Scheme 7).

Cid and co-workers' investigation on the transmetalation step of the Suzuki-Miyaura reaction involved the use of ${ }^{31} \mathrm{P}$ NMR spectroscopy and computational methods. ${ }^{21 \mathrm{a}}$ The authors combined 4-bromo-2-phenylpyridine (31) and phenylboronic acid (1) with $\left(\mathrm{Ph}_{3} \mathrm{P}\right)_{4} \mathrm{Pd}$ and were able to observe a ${ }^{31} \mathrm{P}$ NMR signal at $22.41 \mathrm{ppm}$, which was assigned to $\left(\mathrm{Ph}_{3} \mathrm{P}\right)_{2} \mathrm{PdAr}-\left[(\mathrm{HO})_{3} \mathrm{BAr}\right](\mathbf{3 2})$ (Scheme 8$)$. The predicted structure is based solely on DFT calculations. Although a new peak is observed by ${ }^{31} \mathrm{P}$ NMR spectroscopy, no further structure determination was performed, thus precluding an assignment.

\subsection{Formation of Related M-O-X Complexes.}

The transmetalation of arylboronic acids with complexes of late transition metals such as $\mathrm{Pd}$, $\mathrm{Rh}$, and $\mathrm{Pt}$ has been postulated in cross-coupling reactions as well as conjugate addition reactions. However, the intermediates involved in the transmetalation steps have rarely been observed for these processes. To date, stable Pt and Rh complexes of arylboronic acids have been characterized by single-crystal X-ray diffraction analysis. For example, Osakada ${ }^{28}$ prepared $\mathrm{Pt}-\mathrm{O}-\mathrm{B}$ compound 34 by combining $\left(\mathrm{Me}_{2} \mathrm{PhP}\right)_{2} \mathrm{Pt}(\mathrm{I}) \mathrm{Ph}(\mathbf{3 5})$ and 4methoxyphenylboronic acid (36) with $\mathrm{Ag}_{2} \mathrm{O}$. Complex $\mathbf{3 4}$ is stable in THF until base is added, which induces transmetalation to the diarylplatinum intermediate 37 (Scheme 9).

A similar Rh-O-B complex 38 prepared by Hartwig undergoes transmetalation to form $\left(\mathrm{Et}_{3} \mathrm{P}\right)_{3} \mathrm{Rh}\left(\mathrm{C}_{6} \mathrm{H}_{4} \mathrm{OMe}\right)(\mathbf{3 9})$ when heated to $70{ }^{\circ} \mathrm{C}$ (Scheme 10). ${ }^{29}$ Interestingly, the $\mathrm{Rh}-\mathrm{O}-\mathrm{B}$ complex is proposed to undergo transmetalation without prior activation of the boron center.

A related study from these laboratories on the transmetalation step in the Hiyama-Denmark cross-coupling process described the isolation and single-crystal X-ray diffraction analysis of several compounds containing Pd-O-Si linkages. These complexes enabled a systematic study on the requirements for the transfer of the organic group from silicon to palladium for both neutral (8-Si-4) and anionic (10-Si-5) pathways. ${ }^{12 b}$ These conclusions contradicted the paradigm that organosilicon compounds must be anionically activated to participate in the transmetalation processes. In general, arylsilanolates require anionic activation and react via 10-Si-5 intermediate 41, whereas alkenylsilanolates undergo transmetalation directly from 8$\mathrm{Si}-4$ intermediate $\mathbf{4 2}$ (Figure 4). The ability to perform a similar study with $\mathrm{Pd}-\mathrm{O}-\mathrm{B}$ linkages would be ideal; however, the high propensity for transmetalation at room temperature makes their isolation and characterization difficult in practice. 


\subsection{Rapid Injection NMR.}

Because of the apparently transient nature of species containing $\mathrm{Pd}-\mathrm{O}-\mathrm{B}$ linkages, routine methods such as ESI-MS and NMR spectroscopy are often unable to identify and characterize these highly reactive intermediates. Clearly, fast and low-temperature techniques are required to probe the mechanism of this crucial transmetalation step in the Suzuki-Miyaura reaction, as low barriers $\left(\Delta G^{\dagger}=14-22 \mathrm{kcal} / \mathrm{mol}\right)$ to transmetalation have been calculated. ${ }^{20-22}$ One such technique that has proven invaluable in similar mechanistic studies is rapid injection nuclear magnetic resonance spectroscopy (RI-NMR). ${ }^{30}$ RI-NMR is a conceptually simple technique that was developed by McGarrity and co-workers in 1981 for the observation and characterization of reactive intermediates with short lifetimes. ${ }^{31} \mathrm{In}$ practical terms, an RI-NMR experiment involves charging a substrate, typically the more sensitive compound, in an NMR tube spinning in the probe of an NMR spectrometer. Next, a calibrated syringe assembly is lowered into the magnet to allow for temperature equilibration, shimming, locking, etc., which are then followed by the injection of another reagent. Acquisition begins simultaneously with injection, which allows for rapid data collection. From the integration of the signals, the quantification of each species in solution can be performed with an internal standard. As a result, detailed quantitative kinetic data can be accessed even for fleeting intermediates. If pre-transmetalation intermediates could be generated and characterized by this method, it would provide the first opportunity to interrogate structure and reactivity relationships of this crucial step.

\subsection{Goals of this Study.}

The aim of this project is to provide a complete understanding for the mechanism of the Suzuki-Miyaura reaction by probing the pre-transmetalation intermediate by lowtemperature and RI-NMR spectroscopy along with computational analysis. Specific goals include (1) full characterization of reaction intermediates such as the pre-transmetalation species 4, (2) validation of structure of the proposed intermediates through independent synthesis, (3) demonstration of the kinetic competence of the characterized species containing Pd-O-B linkages to form cross-coupling product, and (4) quantum mechanical simulation of the transmetalation process involving these intermediates by computational modeling. ${ }^{32}$

\section{RESULTS AND DISCUSSION}

\subsection{Preparation and Structural Analysis of Pd-O-B Complexes.}

3.1.1. Preliminary Investigations of trans- $\left(\mathrm{Ph}_{3} \mathrm{P}\right)_{2}\left(4-\mathrm{FC}_{6} \mathrm{H}_{4}\right) \mathrm{Pd}(\mathrm{OH})$ with 4Fluorophenylboronic Acid.-Previous investigations that employed palladium complex $\left[\left(\mathrm{Ph}_{3} \mathrm{P}\right)\left(\mathrm{C}_{6} \mathrm{H}_{5}\right) \mathrm{Pd}(\mathrm{OH})\right]_{2}$ as described above directed our preliminary studies to the use of fluorine-labeled derivatives $\left[\left(\mathrm{Ph}_{3} \mathrm{P}\right)\left(4-\mathrm{FC}_{6} \mathrm{H}_{4}\right) \mathrm{Pd}(\mathrm{OH})\right]_{2}(\mathbf{4 6})$ and 4-fluorophenylboronic acid (47) ${ }^{33}$ using ${ }^{19} \mathrm{~F}$ and ${ }^{31} \mathrm{P}$ NMR spectroscopy. ${ }^{34}$

Addition of 4.0 equiv of $\mathrm{Ph}_{3} \mathrm{P}$ to a THF solution of dinuclear complex 46 resulted in only trace conversion to trans $-\left(\mathrm{Ph}_{3} \mathrm{P}\right)_{2}\left(4-\mathrm{FC}_{6} \mathrm{H}_{4}\right) \mathrm{Pd}(\mathrm{OH})(\mathbf{4 8})$, indicating a thermodynamic preference for the $\mathrm{Pd}-(\mu-\mathrm{OH})-\mathrm{Pd}$ moiety (Scheme 11$).{ }^{35}$ However, the addition of 4 fluorophenylboronic acid (1.0 equiv/Pd in 46$)$ to this solution at $-50{ }^{\circ} \mathrm{C}$ resulted in the 
observation of a new complex by ${ }^{31} \mathrm{P}$ and ${ }^{19} \mathrm{~F}$ NMR spectroscopy. Interestingly, the ${ }^{31} \mathrm{P}$ NMR spectrum displayed two singlets at $-6.5 \mathrm{ppm}\left(\right.$ free $\mathrm{Ph}_{3} \mathrm{P}$ ) and $20.60 \mathrm{ppm}$ in a ratio of 1:1, implying that the complex contained two molecules of $\mathrm{Ph}_{3} \mathrm{P}$ based on the initial stoichiometry of starting materials. The ${ }^{19} \mathrm{~F}$ NMR spectrum displayed a new set of signals at -116.74 and $-125.40 \mathrm{ppm}$ in a 1:1 ratio. The observation of two ${ }^{19} \mathrm{~F}$ NMR resonances excluded the assignment of the new species as the product of transmetalation, trans$\left(\mathrm{Ph}_{3} \mathrm{P}\right)_{2}\left(4-\mathrm{FC}_{6} \mathrm{H}_{4}\right)_{2} \mathrm{Pd}$ (which should appear as a single resonance), and was consistent with the assignment of an unsymmetrical species containing a $\mathrm{Pd}-\mathrm{O}-\mathrm{B}$ linkage such as $\mathbf{4 9}$.

However, the complexity of the aromatic region in the ${ }^{1} \mathrm{H}$ and ${ }^{13} \mathrm{C}$ NMR spectra prohibited assignments, thus making it impossible to unambiguously identify the structure of the new species. Therefore, to clear the aromatic region of interfering signals, the $\mathrm{Ph}_{3} \mathrm{P}$ ligand was replaced with a trialkylphosphine, $i-\mathrm{Pr}_{3} \mathrm{P}$, which readily forms stable mononuclear bisphosphine palladium hydroxide complexes such as trans- $\left(i-\mathrm{Pr}_{3} \mathrm{P}\right)_{2}\left(4-\mathrm{FC}_{6} \mathrm{H}_{4}\right) \mathrm{Pd}(\mathrm{OH})(\mathbf{5 0}){ }^{35}$ Thus, our efforts switched to the study of mononuclear bis-phosphine palladium complexes to identify the key intermediate.

\subsubsection{Reaction of trans-(i- $\left.\mathrm{Pr}_{3} \mathrm{P}\right)_{2}\left(4-\mathrm{FC}_{6} \mathrm{H}_{4}\right) \mathrm{Pd}(\mathrm{OH})$ with 4-} Fluorophenylboronic Acid and 4-Fluorophenylboroxine.-Combination of trans-( $i$ $\left.\mathrm{Pr}_{3} \mathrm{P}\right)_{2}\left(4-\mathrm{FC}_{6} \mathrm{H}_{4}\right) \mathrm{Pd}(\mathrm{OH})(\mathbf{5 0})$ and arylboronic acid 47 with 2.0 equiv of $i$ - $\mathrm{Pr}_{3} \mathrm{P}^{36}$ in THF- $d_{8}$ at $-78{ }^{\circ} \mathrm{C}$, followed by warming to $-60{ }^{\circ} \mathrm{C}$, did not result in the formation of a new intermediate. Upon warming the solution at $-30{ }^{\circ} \mathrm{C}$ for $3 \mathrm{~h}$, quantitative conversion to a new discrete species was observed (Scheme 12, left). The bonding connectivity of the new species was established by the observation of strong, through-space interactions between aryl protons $\mathrm{H}_{\mathrm{b}}$ and $\mathrm{H}_{\mathrm{d}}$ with the methyl hydrogens on the $i$ - $\mathrm{Pr}_{3} \mathrm{P}$ group in the NOESY spectrum. This interaction reveals that both aryl residues were proximal to the phosphines and thus establishes the presence of a Pd-O-B linkage (Figure 5). The identity of the carbon bound to the boron atom $\mathrm{C}(1)$ was revealed in the $\operatorname{HMBC}\left({ }^{1} \mathrm{H}-{ }^{13} \mathrm{C}\right)$ spectrum by the observation of cross peaks between the $\mathrm{BOH}$ hydrogen with a single ${ }^{13} \mathrm{C}$ signal at 138.68 ppm (red bonds).

The coordination geometry at the palladium atom was established by the appearance of the ${ }^{13} \mathrm{C}$ NMR signal of the isopropyl methine carbon $(\mathrm{PCH})$ at $25.38 \mathrm{ppm}$ as an apparent triplet $\left(J_{\mathrm{P}-\mathrm{C}}=10 \mathrm{~Hz}\right)$ owing to virtual coupling, ${ }^{37}$ along with a solitary ${ }^{31} \mathrm{P}$ NMR signal at 29.98 $\mathrm{ppm}$. These data indicate a trans arrangement of phosphine ligands bound to palladium. The valence state at boron was established by the observation of a ${ }^{11} \mathrm{~B}$ NMR signal at $29 \mathrm{ppm}$, indicating a tri-coordinate geometry (6-B-3) 38 that was also seen in the $\mathrm{Pt}^{28}$ and $\mathrm{Rh}^{29}$ complexes, $\mathbf{3 4}$ and $\mathbf{3 8}$, mentioned above.

Support for the structural assignment of complex $\mathbf{5 1}$ was provided by an independent preparation from 4-fluorophenylboroxine (52) (0.33 equiv) and complex $\mathbf{5 0}$ with 2.0 equiv of $i-\mathrm{Pr}_{3} \mathrm{P}$ in THF- $d_{8}$ at $-78{ }^{\circ} \mathrm{C}$, followed by warming to $-60{ }^{\circ} \mathrm{C}$. Under these conditions, a ca. $\mathbf{5 0 \%}$ conversion to complex 51 was observed, with the remainder forming 4,4' difluorobiphenyl cross-coupling product 53 (Scheme 12, right). The similarity of the spectroscopic data from these two independent syntheses, including the NOE cross peaks 
and ${ }^{11} \mathrm{~B}$ NMR chemical shifts, provides compelling support for the structural assignment of 51 as a 6-B-3 palladium(II) complex containing a $\mathrm{Pd}-\mathrm{O}-\mathrm{B}$ linkage.

3.1.3. Reaction of trans-(i-Pr $\left.3{ }_{3} \mathrm{P}\right)_{2}\left(4-\mathrm{FC}_{6} \mathrm{H}_{4}\right) \mathrm{Pd}(\mathrm{I})$ with 4-Fluorophenylboronate Salts.-An alternative preparation of the intermediate involves the direct displacement of halide from the bis-phosphine-ligated oxidative addition product, trans- $\left(i-\mathrm{Pr}_{3} \mathrm{P}\right)_{2}(4-$ $\left.\mathrm{FC}_{6} \mathrm{H}_{4}\right) \mathrm{Pd}(\mathrm{I})(\mathbf{5 4}) .{ }^{32}$ However, treatment of a THF solution of complex 54 with 3.0 equiv of potassium 4-fluorophenylboronate (55) at $-30{ }^{\circ} \mathrm{C}$ in $\mathrm{THF}$ with 2.0 equiv of $i-\mathrm{Pr}_{3} \mathrm{P}$ resulted in no reaction (Scheme 13, left). Even upon warming to $30^{\circ} \mathrm{C}$, no cross-coupling product $\mathbf{5 3}$ was observed. The lack of reaction is most likely due to the steric hindrance at the palladium center provided by the bulky phosphine ligands, as well as the low solubility of $\mathbf{5 5}$ in THF.

To activate the palladium center toward nucleophilic attack, $\mathbf{5 4}$ was combined with 3.0 equiv of thallium 4-fluorphenylboronate (56) containing 1.0 equiv of $i$ - $\operatorname{Pr}_{3} \mathrm{P}$ and dibenzo-22crown- $6^{39}$ to facilitate halide abstraction (Scheme 13, right). Although only a $10 \%$ conversion to $\mathbf{5 1}$ was observed by ${ }^{19} \mathrm{~F}$ and ${ }^{31} \mathrm{P}$ NMR spectroscopy, the experiment demonstrated that intermediate $\mathbf{5 1}$ could be formed directly from complex $\mathbf{5 4}$.

3.1.4. Attempts To Generate an 8-B-4 Complex from 51.-The formation of 6-B-3 complex $\mathbf{5 1}$ may arise either from a kinetically generated 8-B-4 complex $\mathbf{5 7}$ followed by rapid elimination of a single molecule of water or from displacement of a molecule of water from ion pair $\mathbf{5 7}^{\prime}$, which may be generated by protonation of complex $\mathbf{5 0}$ by boronic acid $\mathbf{4 7}$ (Scheme 14) ${ }^{40}$ Because these experiments were performed in anhydrous THF, it is conceivable that the 8-B-4 complex $\mathbf{5 7}$ is thermodynamically unstable. Thus, a number of attempts to add water back were undertaken, beginning with generating $\mathbf{5 1}$ in $\mathrm{THF} / \mathrm{H}_{2} \mathrm{O}$ (99:1) mixtures; however, no changes in the ${ }^{31} \mathrm{P},{ }^{19} \mathrm{~F}$, or ${ }^{11} \mathrm{~B}$ NMR spectra were observed at $-30{ }^{\circ} \mathrm{C}$ (Scheme 14).

Next, the use of $\mathrm{CsOH} \cdot \mathrm{H}_{2} \mathrm{O}$ was explored by combining 6-B-3 complex 51 (from $\mathbf{5 0}$ and 47, vide supra) in $\mathrm{THF}$ at $-78{ }^{\circ} \mathrm{C}$ with a solution of $\mathrm{CsOH} \cdot \mathrm{H}_{2} \mathrm{O}$ (5.0 equiv) in methanol. The sample was monitored at $-30{ }^{\circ} \mathrm{C}$, but no changes in the ${ }^{19} \mathrm{~F},{ }^{31} \mathrm{P}$, or ${ }^{11} \mathrm{~B}$ NMR spectra were observed. However, after the sample was warmed in $10{ }^{\circ} \mathrm{C}$ intervals up to $20^{\circ} \mathrm{C}$, cesium 4fluorophenylboronate $\mathbf{5 9}$ and complex $\mathbf{5 0}$ were observed by ${ }^{19} \mathrm{~F}$ and ${ }^{31} \mathrm{P}$ NMR spectroscopy, indicating that the arylboronic acid had been displaced from the palladium center (Scheme 15). This experiment supported the notion that arylboronate complexes such as $\mathbf{5 7}$ and $\mathbf{5 8}$ are indeed unstable. The reason for their instability was revealed by thermochemical calculations as detailed below.

3.1.5. Thermochemical Calculations on 6-B-3 and 8-B-4 Complexes.-To gain further insight into the lack of stability of 8-B-4 complex 57, ground-state equilibrium energies were calculated using M06-2X/6-31G(d) on B3LYP/6-31(d)-optimized structures with a THF continuum solvent field. The loss of water from an initially formed 8-B-4 complex $\mathbf{5 7}$, yielding 6-B-3 complex $\mathbf{5 1}$, was found to be highly exergonic $\left(\Delta G^{\circ}=-10.8\right.$ $\mathrm{kcal} / \mathrm{mol})$. Surprisingly, the entropic advantage $\left(\Delta S^{\circ}=0.048 \mathrm{kcal} /(\mathrm{mol} \cdot \mathrm{K})\right)$ is not offset by the expected enthalpic disadvantage of creating a coordinatively unsaturated boron $\left(\Delta H^{\circ}=\right.$ $1.0 \mathrm{kcal} / \mathrm{mol}$ ) (Figure 6). 
Inspection of space-filling models of $\mathbf{5 7}$ reveals that the $\mathrm{OH}$ groups on boron penetrate the van der Waals radii of the isopropyl methyl groups on phosphorus, thus destabilizing the four-coordinate geometry. Therefore, the instability of $\mathbf{5 7}$ is not related to the medium, but rather to the bulk of the two $i-\operatorname{Pr}_{3} \mathrm{P}$ groups attached to palladium. The solution to this problem then became obvious: remove a phosphine ligand from the complex. Indeed, calculation of the ground-state energies for monoligated complexes 60 and $\mathbf{6 1}$ reversed the equilibrium position, now substantially favoring the 8-B-4 complex $\left(\Delta G^{\circ}=-6.9 \mathrm{kcal} / \mathrm{mol}\right)$ despite an unfavorable entropy $\left(\Delta S^{\circ}=-0.045 \mathrm{kcal} /(\mathrm{mol} \cdot \mathrm{K})\right)$. This preference is driven by the overwhelming enthalpic benefit of saturating the valences on boron $\left(\Delta H^{\circ}=-17.9 \mathrm{kcal} / \mathrm{mol}\right)$.

Accordingly, the focus of the investigation switched to the study of monoligated arylpalladium(II) complexes to enable the generation of the long-sought 8-B-4 activated adduct.

\subsubsection{Reaction of $\left[\left(\mathrm{i}-\mathrm{Pr}_{3} \mathrm{P}\right)\left(4-\mathrm{FC}_{6} \mathrm{H}_{4}\right) \mathrm{Pd}(\mathrm{OH})\right]_{2}$ with 4-Fluorophenylboronic} Acid.-Addition of a THF solution of 47 (1.0 equiv/Pd) to dimeric complex $\left[\left(i-\mathrm{Pr}_{3} \mathrm{P}\right)(4-\right.$ $\left.\left.\mathrm{FC}_{6} \mathrm{H}_{4}\right) \mathrm{Pd}(\mathrm{OH})\right]_{2}(62)^{41}$ in $\mathrm{THF}-d_{8}$ at $-78{ }^{\circ} \mathrm{C}$, followed by warming to $-50{ }^{\circ} \mathrm{C}$, resulted in no change in the ${ }^{1} \mathrm{H}$ NMR spectrum (Scheme 16). However, the ${ }^{19} \mathrm{~F}$ NMR spectrum displayed a sharp signal for $\mathrm{F}_{\mathrm{a}}$ at $-123.35 \mathrm{ppm}$ but an extremely broadened signal for $\mathrm{F}_{\mathrm{b}}$ at approximately $-111.98 \mathrm{ppm}$, signifying a dynamic process. Upon cooling the solution to $-100{ }^{\circ} \mathrm{C}$, new signals appeared in the aromatic region of the ${ }^{1} \mathrm{H}$ NMR spectrum, along with complete loss of the signals of $\mathbf{6 2}$, but surprisingly with $50 \%$ of 47 remaining (Scheme 16 , left). The incomplete consumption of the boronic acid could be interpreted as an unfavorable equilibrium or a different stoichiometry of complexation. The former interpretation was eliminated by the addition of 2.0 equiv/Pd of 47 to complex 62, whereupon no further incorporation of the arylboronic acid was observed. The connectivity in complex 63 was established by the observation of 1D-NOE, positive cross peaks between $\mathrm{H}_{\mathrm{b}}, \mathrm{H}_{\mathrm{d}}$, and the bridging $\mathrm{OH}$ group with the methyl hydrogens on the $i-\mathrm{Pr}_{3} \mathrm{P}$ group. The observation of positive NOE cross peaks indicates slow molecular movements (tumbling) consistent with the larger molecular size of the 2:1 complex. Moreover, the resonances for $\mathrm{H}_{\mathrm{b}}$ and for the methyl hydrogens on the $i-\operatorname{Pr}_{3} \mathrm{P}$ group were exceptionally broadened at $-100{ }^{\circ} \mathrm{C}$, indicating an observable barrier to rotation about both the $\mathrm{P}-\mathrm{Pd}$ and aryl-Pd bonds. On the basis of the available data, the structure of this complex was assigned as the bridged bis-arylpalladium arylboronate complex 63 , which represents direct insertion of 47 into the dimeric complex $\mathbf{6 2}$ without further dissociation. 42

The unexpected 2:1 stoichiometry of complex 63 was confirmed by combining a THF- $d_{8}$ solution of $47\left(0.5\right.$ equiv/Pd) with a THF- $d_{8}$ solution of 62 at $-60{ }^{\circ} \mathrm{C}$, followed by cooling to $-100{ }^{\circ} \mathrm{C}$, whereupon a quantitative conversion to 63 was observed. The ${ }^{11} \mathrm{~B}$ NMR spectrum of complex 63 did not reveal a discrete signal, owing to the rapid exchange between the arylboronic acid 47 and the palladium hydroxide complex 62, as confirmed by EXSY experiments.

\subsubsection{Reaction of $\left[\left(i-\mathrm{Pr}_{3} \mathrm{P}\right)\left(4-\mathrm{FC}_{6} \mathrm{H}_{4}\right) \mathrm{Pd}(\mathrm{I})\right]_{2}$ with Thallium 4-} Fluorophenylboronate.-To support the structural assignment of complex 63 , an independent synthesis was performed by combining 1.5 equiv/Pd of thallium arylboronate 
56 with $\left[\left(i-\mathrm{Pr}_{3} \mathrm{P}\right)\left(4-\mathrm{FC}_{6} \mathrm{H}_{4}\right) \mathrm{Pd}(\mathrm{I})\right]_{2}(\mathbf{6 4})^{32}$ in THF $-d_{8}$ at $-78{ }^{\circ} \mathrm{C}$, followed by warming to -50 ${ }^{\circ} \mathrm{C}$. Upon cooling the mixture to $-100{ }^{\circ} \mathrm{C}$, the identity of complex $\mathbf{6 3}$ was confirmed in a 1:1 ratio with cross-coupling product 53 by ${ }^{1} \mathrm{H},{ }^{19} \mathrm{~F}$, and ${ }^{31} \mathrm{P}$ NMR spectroscopy, indicating the ability to form the Pd-O-B linkage in 63 with complex 64 directly (Scheme 16, right). ${ }^{43}$

3.1.8. Variable-Temperature NMR Analysis of Complex 63.-The activation energy of exchange between complex 63 and arylboronic acid 47 was measured by variabletemperature NMR spectroscopy. The ${ }^{19} \mathrm{~F}$ NMR spectra of a 1:1 ratio of complex $\mathbf{6 3}$ and unbound $\mathbf{4 7}$ were recorded over a course of multiple experiments at temperatures ranging from -100 to $-10{ }^{\circ} \mathrm{C}$ in THF (Figure 7). The rapid exchange of 63 and unbound 47 is evidenced by the overlapping and broadening of their ${ }^{19} \mathrm{~F}$ NMR signals at higher temperatures $\left(>-50^{\circ} \mathrm{C}\right)$, and the slow exchange is evidenced at lower temperatures by the decoalescence of the ${ }^{19} \mathrm{~F}$ signals into well-resolved peaks. An approximate coalescence temperature $\left(T_{\mathrm{c}}\right)$ was measured at $-40{ }^{\circ} \mathrm{C}$ by the signals merging with the baseline. The rate constant $k_{\mathrm{c}}$ at coalescence was measured using $k_{\mathrm{c}}=\pi \Delta v / \sqrt{2}$, where $\Delta v$ is the maximum chemical shift difference $(1068 \mathrm{~Hz})$ between 63 and 47 at $-100{ }^{\circ} \mathrm{C}$. Using the Eyring equation $\Delta G_{\mathrm{e}}^{*}=-R T_{\mathrm{c}} \ln \left(k_{\mathrm{c}} h / k_{\mathrm{B}} T_{\mathrm{c}}\right)$, the activation of exchange was measured approximately as $\Delta G_{\mathrm{e}}^{\ddagger} \approx 10 \mathrm{kcal} / \mathrm{mol}$. This low barrier of exchange between 63 and 47 suggests that the broad ${ }^{11} \mathrm{~B}$ NMR signal is caused by rapid changes in the coordination state of boron.

\subsubsection{Reaction of $\left[\left(\mathrm{t}-\mathrm{Bu}_{3} \mathrm{P}\right)\left(4-\mathrm{FC}_{6} \mathrm{H}_{4}\right) \mathrm{Pd}(\mathrm{OH})\right]_{2}$ with 4-Fluorophenylboronic}

Acid.-In an attempt to form a complex with $1: 1 \mathrm{Pd} / \mathrm{B}$ stoichiometry, the larger $t$ - $\mathrm{Bu}_{3} \mathrm{P}$ ligand was employed to weaken the $\mathrm{Pd}-(\mu-\mathrm{OH})-\mathrm{Pd}$ bonds and form a T-shaped palladium hydroxide complex. Thus, addition of a THF- $d_{8}$ solution of complex 65 to a THF- $d_{8}$ solution of 47 (1.0 equiv/Pd) at $-78{ }^{\circ} \mathrm{C}$, followed by warming to $-60{ }^{\circ} \mathrm{C}$, produced no new complexes. However, upon cooling the solution to $-100{ }^{\circ} \mathrm{C}$, a new complex emerged with complete consumption of $\mathbf{6 7}$, with 1.0 equiv of $\mathbf{4 7}$ remaining (Scheme 17). The structure of this complex was assigned as the bridged bis-arylpalladium arylboronate complex 67 , by analogy to complex 63 . Two discrete $\mathrm{H}_{\mathrm{b}}$ signals were observed at $-100{ }^{\circ} \mathrm{C}$, wherein the barrier to rotation about the palladium aryl bond was found to be $\sim 9 \mathrm{kcal} / \mathrm{mol} .{ }^{44} \mathrm{Thus}$, even the bulkier $t$ - $\mathrm{Bu}_{3} \mathrm{P}$ ligand could not effect dissociation of the 2:1 complex.

\subsubsection{Reaction of $\left[\left(i-\mathrm{Pr}_{3} \mathrm{P}\right)\left(4-\mathrm{FC}_{6} \mathrm{H}_{4}\right) \mathrm{Pd}(\mathrm{OH})\right]_{2}$ with 4-Fluorophenylboronic}

Acid in $\mathrm{THF} / \mathrm{CH}_{3} \mathrm{OH}$.-The surprising formation of 2:1 complex 63 raised a number of questions regarding the origin of its stability. Because this structure is heavily dependent upon the bridging capability of various oxygen atoms, it seemed logical to examine the effect of other donors on the stability of this complex.

Injection of $\mathrm{CH}_{3} \mathrm{OH}^{45}$ (60 $\mu \mathrm{L}$ ) into a THF- $d_{8}$ solution of $\mathbf{6 3}$ with 1.0 equiv of $\mathbf{4 7}$ (from 62 and $\mathbf{4 7}$, vide supra) at $-55{ }^{\circ} \mathrm{C}$ resulted in the quantitative formation of a new species, 68 (Scheme 18, left). Attempts to confirm the incorporation of methanol into complex $\mathbf{6 8}$ by NMR spectroscopy were unsuccessful, most likely because of rapid exchange with free methanol in solution. Therefore, the identity of complex $\mathbf{6 8}$ was verified by the reaction of 1.0 equiv/Pd 4-fluorophenyldimethoxyboronate 69 with palladium dimer 62 at $-78{ }^{\circ} \mathrm{C}$ in THF- $d_{8} / \mathrm{CD}_{3} \mathrm{OD}$, followed by warming to $-55^{\circ} \mathrm{C}$, whereupon a quantitative formation of 
complex 68 was observed by ${ }^{1} \mathrm{H}$ and ${ }^{13} \mathrm{C}$ NMR spectroscopy (Scheme 18 , right). This experiment clearly demonstrates that methanol does not convert the starting binuclear arylpalladium hydroxide complex into a T-shaped complex but instead creates a more Lewis acidic boron atom by replacing both hydroxyl groups with methoxy groups. ${ }^{46}$

Nevertheless, the presence of a Pd-O-B linkage in $\mathbf{6 8}$ was established by the observation of cross peaks between the methyl hydrogens on the $i-\mathrm{Pr}_{3} \mathrm{P}$ with both $\mathrm{H}_{\mathrm{b}}$ and $\mathrm{H}_{\mathrm{d}}$ using NOE spectroscopy. The ${ }^{11} \mathrm{~B}$ NMR signal at $9 \mathrm{ppm}$ was well within the chemical shift regime for tetra-coordinate boron (8-B-4) complexes. ${ }^{47}$

\subsubsection{Reaction of $\left[\left(\mathrm{Ph}_{3} \mathrm{P}\right)\left(4-\mathrm{FC}_{6} \mathrm{H}_{4}\right) \mathrm{Pd}(\mathrm{OH})\right]_{2}$ with 4-Fluorophenylboronic} Acid in $\mathrm{THF} / \mathrm{CH}_{3} \mathrm{OH}$.- To establish if similar 1:1 complexes can be formed with other ligands, $\left[\left(\mathrm{Ph}_{3} \mathrm{P}\right)\left(4-\mathrm{FC}_{6} \mathrm{H}_{4}\right) \mathrm{Pd}(\mathrm{OH})\right]_{2}(\mathbf{4 6})$ was combined with 1.0 equiv/Pd of 47 at $-78{ }^{\circ} \mathrm{C}$ in THF- $d_{8} / \mathrm{CD}_{3} \mathrm{OD}$, followed by warming to $-55{ }^{\circ} \mathrm{C}$. A new complex $\mathbf{7 0}$ was formed quantitatively, which displays spectroscopic characteristics similar to those of the other complexes $\left({ }^{1} \mathrm{H},{ }^{13} \mathrm{C},{ }^{19} \mathrm{~F},{ }^{31} \mathrm{P}\right.$, and $\left.{ }^{11} \mathrm{~B} \mathrm{NMR}\right)$, and for which HMBC and HSQC experiments established connectivity (Scheme 19).

\subsubsection{Reaction of [(DPPF)(4-FC $\left.\left.{ }_{6} \mathrm{H}_{4}\right) \mathrm{Pd}(\mathrm{OH})\right]$ with 4-Fluorophenylboronic}

Acid in THF.-The preference for a tri-coordinate boron atom in 6-B-3 complex $\mathbf{5 1}$ arose from the presence of two bulky $i-\operatorname{Pr}_{3} \mathrm{P}$ ligands arranged in a trans configuration about the palladium (F- and B-strain). ${ }^{48}$ It was of interest to investigate whether arranging the ligands in a cis coordination geometry would allow the boron atom to adopt a tetra-coordinate state. Therefore, following literature precedent, ${ }^{49}(\mathrm{DPPF})\left(4-\mathrm{FC}_{6} \mathrm{H}_{4}\right) \mathrm{Pd}(\mathrm{OH})$ was prepared by combining complex $\mathbf{4 6}$ with 2.0 equiv of DPPF in THF to form complex $\mathbf{7 1}$ (Scheme 20).

Next, complex 71 was combined with arylboronic acid 47 at $-55^{\circ} \mathrm{C}$, which resulted in the quantitative conversion to a new species, $\mathbf{7 2}$ (Scheme 21). Complex $\mathbf{7 2}$ was characterized by ${ }^{1} \mathrm{H},{ }^{31} \mathrm{C},{ }^{19} \mathrm{~F},{ }^{11} \mathrm{~B}$, and ${ }^{31} \mathrm{P}$ NMR spectroscopy, with the HMBC $\left({ }^{1} \mathrm{H}-{ }^{13} \mathrm{C}\right.$ and $\left.{ }^{1} \mathrm{H}-{ }^{31} \mathrm{P}\right)$ and HSQC $\left({ }^{1} \mathrm{H}-{ }^{31} \mathrm{C}\right)$ experiments establishing the connectivity.

At $-55{ }^{\circ} \mathrm{C}$, the assignment of the $\mathrm{P}(1)$ atom $(11.47 \mathrm{ppm})$ in $\mathbf{7 2}$ was enabled by the observation of trans couplings across the $\mathrm{Pd}$ center to $\mathrm{H}_{\mathrm{b}}\left({ }^{4} J_{\mathrm{P}-\mathrm{H}}\right)$ and to $\mathrm{H}_{\mathrm{a}}\left({ }^{5} J_{\mathrm{P}-\mathrm{H}}\right)$, establishing a trans relationship between $\mathrm{P}(1)$ and the aryl group bound to palladium. ${ }^{50}$ The ${ }^{11} \mathrm{~B}$ NMR chemical shift was merged with the baseline, suggesting a rapid equilibrium between $\mathbf{7 2}$ and starting materials. ${ }^{51}$

\subsection{Kinetic Analysis of the Complexes Containing Pd-O-B Linkages.}

The ability to generate pre-transmetalation intermediates with different coordination environments around both the boron and palladium atoms provided the opportunity to interrogate kinetic aspects of the transmetalation event. Specifically, the effect of ligand and organoboron source was probed by monitoring the decay of $\mathrm{Pd}-\mathrm{O}-\mathrm{B}$-containing intermediates and formation of cross-coupling products by ${ }^{19} \mathrm{~F}$ NMR spectroscopy.

3.2.1. Kinetic Analysis of Complex 63 from $\left[\left(i-\mathrm{Pr}_{3} \mathrm{P}\right)\left(4-\mathrm{FC}_{6} \mathrm{H}_{4}\right) \mathrm{Pd}(\mathrm{OH})\right]_{2}$ and 4Fluorophenylboronic Acid.-Complex $\mathbf{6 3}$ was prepared as described in section 3.1.6 by 
the addition of a THF solution of $\mathbf{4 7}\left(1.0\right.$ equiv/Pd) to a THF solution of 62 at $-78{ }^{\circ} \mathrm{C}$. To establish the kinetic behavior, the sample was warmed to $-30{ }^{\circ} \mathrm{C}$, and the ${ }^{19} \mathrm{~F}$ NMR signals for both 53 and $\mathbf{6 3}$ were monitored. This analysis revealed a clean, first-order decay of the arylpalladium complex $\mathbf{6 3}$ and formation of $\mathbf{5 3}$ with $k_{\mathrm{obs}}=(5.78 \pm 0.13) \times 10^{-4}$ and $(7.59 \pm$ $0.58) \times 10^{-4} \mathrm{~s}^{-1}$, respectively. The similarity of rates for appearance of $\mathbf{5 3}$ and consumption of $\mathbf{6 3}$ suggests that transmetalation is the ratedetermining step for this process.

The proposal that arylboronate complex $\mathbf{6 3}$ converts to $\mathbf{6 0}$ prior to transmetalation is supported by several lines of evidence. ${ }^{52}$ First, the kinetic behavior of arylpalladium complex 68 in THF/ $\mathrm{CH}_{3} \mathrm{OH}$ (a fully characterized 1:1 complex related to 60 ) revealed a clean, first-order decay of $\mathbf{6 8}$ and formation of $\mathbf{5 3}$ with $k=(1.55 \pm 0.09) \times 10^{-3}$ and $(1.41 \pm$ $0.02) \times 10^{-3} \mathrm{~s}^{-1}$, respectively. These values are very similar to the rates observed with complex 63 in THF. Moreover, the first-order behavior confirms that the transmetalation is an intramolecular process. Second, an Arrhenius analysis was performed by measuring the rates of formation of $\mathbf{5 3}$ (from $\mathbf{6 2}$ and 1.0 equiv/Pd of $\mathbf{4 7}$ ) at four different temperatures ranging from -40 to $-10{ }^{\circ} \mathrm{C}$ in THF. Upon plotting $\ln (k / T)$ vs $T^{-1}$, a linear slope was obtained, allowing the enthalpic $\left(\Delta H_{243.15}^{\ddagger}=15.98 \pm 0.79 \mathrm{kcal} / \mathrm{mol}\right)$ and entropic $\left(\Delta S_{243.15}^{\ddagger}=-0.0069 \pm 0.0032 \mathrm{kcal} / \mathrm{mol}\right)$ activation parameters to be extracted using the Eyring equation. The similarity of the measured and calculated activation parameters (see section 3.3.1) strongly suggests that complex $\mathbf{6 3}$ rearranges to $\mathbf{6 0}$ prior to transmetalation (Table 1).

\subsubsection{Effect of Phosphine Ligand on the Rate of the Transmetalation Step.-}

To establish the effect of phosphine ligand (DPPF, $i-\mathrm{Pr}_{3} \mathrm{P}, \mathrm{Ph}_{3} \mathrm{P}$ ) on the rate of transmetalation, complexes $\mathbf{7 1}, \mathbf{6 2}$, and $\mathbf{4 6}$ were combined separately with 4fluorophenylboronic acid (47) (1.0 equiv/Pd) at $-10{ }^{\circ} \mathrm{C}$ to generate $\mathbf{7 2}, \mathbf{6 0}$, and $\mathbf{7 3}$, respectively, such that their ${ }^{19} \mathrm{~F}$ NMR signals could be monitored. ${ }^{53}$ Each complex exhibited first-order decay, providing accurate values for $k_{\mathrm{obs}}$ (Table 2). The slower reaction rate of the DPPF-ligated complex compared to those of the $\mathrm{Ph}_{3} \mathrm{P}-$ and $i$ - $\mathrm{Pr}_{3} \mathrm{P}$-ligated complexes suggests that a ligand dissociation event takes place prior to the transmetalation event in complex 72. The rate of transmetalation from the $\mathrm{Ph}_{3} \mathrm{P}$ complex $\mathbf{7 3}$ was slightly faster than that from the $i-\mathrm{Pr}_{3} \mathrm{P}$ complex $\mathbf{6 0}$, indicating that the increased rate is not related to the size of the ligand, but rather to the electrophilicity of the palladium center. ${ }^{54}$ From these data, the rate of the transmetalation process follows the trend $\mathrm{Ph}_{3} \mathrm{P}>i-\mathrm{Pr}_{3} \mathrm{P}>\mathrm{DPPF}$, highlighting the need for generating a coordinatively unsaturated and electrophilic palladium atom during the transmetalation process.

3.2.3. Kinetic Analysis of 6-B-3 Complex 51.-Complex 51 (generated from 47 and 50, see section 3.1.2) was thermally stable at $-30{ }^{\circ} \mathrm{C}$ for more than $24 \mathrm{~h}$ in the presence of $i$ $\mathrm{Pr}_{3} \mathrm{P}$, indicating that a higher temperature would be needed to form cross-coupling product 53. In fact, warming a THF solution of $\mathbf{5 1}$ to $20^{\circ} \mathrm{C}$ resulted in the formation of $\mathbf{5 3}$. However, it did not display the first-order behavior observed for the previous complexes, but rather exhibited S-shaped concentration vs time curves, indicating that the $k_{\mathrm{obs}}$ increases over the course of the reaction, which is characteristic of autocatalysis or an induction period. The 
kinetic order in phosphine was determined by monitoring the rate of decay of $\mathbf{5 1}$ in THF solutions containing increasing amounts of $i-\mathrm{Pr}_{3} \mathrm{P}$, ranging from 97 to $294 \mathrm{mM}$ at $20^{\circ} \mathrm{C}$. The S-shaped kinetic profiles were fitted, and $v_{\max }$ was extracted from the data. ${ }^{55}$ Plotting $\log \left[v_{\max }\right]$ vs $\log \left[i-\mathrm{Pr}_{3} \mathrm{P}\right]$ provided a straight line with a slope of $-1.01 \pm 0.05$, consistent with an inverse dependence on phosphine (Table 3). This dependence indicates that a phosphine ligand must dissociate in a pre-equilibrium process that leads to putative 14-electron palladium complex 61 (Figure 8). The requirement for this reveal high barriers for direct transmetalation from intermediates such as $\mathbf{5 1} .^{20}$

\subsubsection{Probing the Transmetalation from 6-B-3 Complex 51: Autocatalysis}

Explained.-The S-shaped kinetic profiles observed for the reactions outlined above are indicative of an increase in rate during the reaction, which is likely the result of a product catalyzing its own formation. The stoichiometrically mandated products of this crosscoupling reaction are biaryl $\mathbf{5 3},\left(i-\mathrm{Pr}_{3} \mathrm{P}\right)_{2} \mathrm{Pd}$, and boric acid. Because $\mathbf{5 3}$ is an inert organic compound, it is highly unlikely that it can serve as a catalyst. On the other hand, the initial palladium-containing byproduct, $\left(i-\mathrm{Pr}_{3} \mathrm{P}\right)_{n} \mathrm{Pd}$, is a more likely candidate for accelerating the process by scavenging $i-\mathrm{Pr}_{3} \mathrm{P}$ from $\mathbf{5 1}$. However, under the conditions of the kinetic measurements which employ an excess of $i-\operatorname{Pr}_{3} \mathrm{P}(2.85-8.62$ equiv/ $\mathrm{Pd})$, the $\operatorname{Pd}(0)$ species should already be saturated, thus precluding the possibility of autocatalysis. Interestingly, upon dissolving $\left(i-\mathrm{Pr}_{3} \mathrm{P}\right)_{3} \mathrm{Pd}$ in THF, both $\left(i-\mathrm{Pr}_{3} \mathrm{P}\right)_{2} \mathrm{Pd}$ and $i-\mathrm{Pr}_{3} \mathrm{P}$ are observed, which means the palladium center cannot accept a third ligand in solution. ${ }^{56}$ Not surprisingly, upon the addition of 0.25 equiv of $\left(i-\mathrm{Pr}_{3} \mathrm{P}\right)_{2} \mathrm{Pd}$ to a solution of $\mathbf{5 1}$ with 3.81 equiv of $i-\mathrm{Pr}_{3} \mathrm{P}$, S-shaped profiles were still observed with $V_{\max }=(2.86 \pm 0.36) \times 10^{-3} \mathrm{mM} \mathrm{s}^{-1}$, which was within error of the $v_{\max },(3.24 \pm 0.12) \times 10^{-3} \mathrm{mM} \mathrm{s}^{-1}$, obtained in the absence of the additive (Table 3, entry 5). The persistence of autocatalytic behavior confirms that no order dependence is observed for the $\operatorname{Pd}(0)$ byproducts during the reaction, leaving only the boric acid as the remaining culprit for the S-shaped profiles. Unfortunately, boric acid could not be tested because of its low solubility in THF, suggesting that no further options existed. However, inspection of Figure 8 reveals that, if transmetalation is occurring via 61, boric acid is in fact not formed directly. Rather, the immediate byproduct of transmetalation is metaboric acid, which scavenges the water molecule generated during the formation of $\mathbf{5 1}$ to form boric acid. Thus, the role of water now becomes a factor worth investigating for the origin of autocatalysis.

One reasonable hypothesis for the role of water is that it can bind to the boron atom in $\mathbf{6 1}$, forming 8-B-4 species $\mathbf{6 0}$ (Figure 8), thus opening a second pathway that lowers the equilibrium concentration of $61 .{ }^{57}$ Despite the fact that 60 is itself kinetically competent for transmetalation (section 3.2.1), in the presence of excess $i-\operatorname{Pr}_{3} \mathrm{P}$ this species rapidly reverses back to 51, thus constituting a parasitic as opposed to a productive pathway. Moreover, if product formation were occurring via 8-B-4 complex 60, then the highest rate should be observed at the beginning of the reaction because $\mathbf{6 0}$ would be at its highest concentration. To provide support for this hypothesis, it was necessary to demonstrate the ability to independently convert 60 to 51 in the presence of $i-\operatorname{Pr}_{3} \mathrm{P}$. Thus, a solution of complex 63 was prepared from 47 (1.0 equiv/Pd) and 62 in THF at $-78{ }^{\circ} \mathrm{C}$, followed by warming to $-55^{\circ} \mathrm{C}$. As previously described, a mixture of $\mathbf{6 3}$ (which is in equilibrium with 60 ) and 1.0 equiv of 
47 was observed by ${ }^{31} \mathrm{P}$ and ${ }^{19} \mathrm{~F}$ NMR analysis (Scheme 22). Upon addition of $60 \mu \mathrm{L}$ of a 1.6 M THF solution of $i-\mathrm{Pr}_{3} \mathrm{P}$ at $-78^{\circ} \mathrm{C}$ to this solution, followed by warming to $20{ }^{\circ} \mathrm{C}$, 6B-3 complex 51 was observed, along with minor amounts of cross-coupling product $\mathbf{5 3}$. The kinetic behavior of complex $\mathbf{5 1}$ generated by this route was found to have a $V_{\max }$ matching that seen for the formation of $\mathbf{5 1}$ from $\mathbf{4 7}$ and $\mathbf{5 0}$ (Table 3, entries 2 and 7). Thus, it appears that water is in fact inhibiting the cross-coupling by shunting $\mathbf{6 1}$ to 8 -B-4 intermediate $\mathbf{6 0}$, which is captured by excess phosphine to arrive at resting state $\mathbf{5 1}$.

Further support for the inhibitory role of water was obtained by monitoring the reaction of 6$\mathrm{B}-3$ complex 51 containing 5.41 equiv of $i-\mathrm{Pr}_{3} \mathrm{P}$ and an additional 10.0 equiv of water. The $V_{\max }$ was indeed found to be slower than with no additional water present (Table 3, entry 6). This observation suggests that, if complex $\mathbf{6 0}$ were being formed (from $\mathbf{6 1}$ and water), then it reverts to $\mathbf{5 1}$ by recombination with $i-\operatorname{Pr}_{3} \mathrm{P}$ faster than it undergoes transmetalation at $20{ }^{\circ} \mathrm{C}$. Finally, if the role of water is to inhibit the transmetalation via $\mathbf{6 1}$, then generating $\mathbf{6 1}$ in the absence of water should remove the autocatalytic behavior.

In fact, the water-free preparation of $\mathbf{5 1}$ has already been described as part of the structural proof (Scheme 12) by combination of complex $\mathbf{5 0}$ and arylboroxine $\mathbf{5 2}$ (0.33 equiv) in THF. Repeating this procedure at $-78{ }^{\circ} \mathrm{C}$ in the presence of 15.03 equiv of $i-\operatorname{Pr}_{3} \mathrm{P}$ allowed the intrinsic reactivity of $\mathbf{5 1}$ to be determined (Scheme 23). ${ }^{58}$ Clean first-order kinetic behavior was observed for decay of $51\left((1.25 \pm 0.60) \times 10^{-4} \mathrm{~s}^{-1}\right)$ and formation of $53((7.14 \pm 0.43) \times$ $10^{-5} \mathrm{~s}^{-1}$ ) (Scheme 23). Thus, the observation of normal first-order kinetic behavior for $\mathbf{6 1}$ in the absence of water provides a compelling albeit unexpected explanation for the observation of autocatalysis. The equivalent of water generated from the combination of $\mathbf{4 7}$ and 50 (Figure 8) inhibits the transmetalation via $\mathbf{6 1}$ by redirecting this intermediate to 8B-4 complex $\mathbf{6 0}$, which is converted to resting state $\mathbf{5 1}$ in the presence of excess $i-\operatorname{Pr}_{3} \mathrm{P}$. However, as the reaction proceeds, the metaboric acid byproduct $(\mathrm{BO}(\mathrm{OH}))$ scavenges the water to form boric acid and consumes the inhibitor (water), thus accounting for the observed autocatalytic behavior (Figure 8). This observation also provides compelling evidence that a tri-coordinate boron species can undergo unassisted transmetalation.

\subsection{Computational Analysis of the Reaction Profile for Complexes Containing Pd-O-B Linkages.}

To gain further insight into the transmetalation step, transition-state structures were calculated at the M06-2X/6-31G(d) level on B3LYP/6-31(d)-optimized structures with a THF continuum solvent field for the activated 8-B-4 complex 60, along with unactivated 6B-3 complex 61. Our previous computational investigation of arylpalladium arylsilanolate complexes revealed a significant difference in the energy profiles of isomeric arylpalladium complexes. ${ }^{12 \mathrm{~b}}$ These three-coordinate species can exist in two configurations about palladium in which an empty site is either trans to the aryl group (TA) or trans to the phosphine (TP). For completeness, both isomers were calculated for all the ground states, intermediates, transition states, and products.

3.3.1. Computational Analysis of Complex 60.-The energy profile for the transmetalation event from 8-B-4 complex 60 is summarized in Figure 9. The 
experimentally observed ground-state structure $60-G S$ has two bridging hydroxyl groups bound to the palladium atom; however, for the transmetalation event to take place, an empty coordination site is needed. The two bridging hydroxyl groups are nonequivalent: one is trans to the aryl group (red), and the other is trans to the phosphine (black). Cleavage of either of these groups will lead to their respective coordinatively unsaturated complexes described above, which are " $T A$ " (trans to aryl, red) or " $T P$ ' (trans to phosphine, black). The energies of transition states $\mathbf{6 0}$-InterTS-TA and $\mathbf{6 0}$-InterTS-TP for the formation for the two different T-shaped complexes are 9.37 and $8.44 \mathrm{kcal} / \mathrm{mol}$, respectively, whereas the energies of the resulting intermediates 60 -Inter-TA and 60 -Inter-TP are 8.93 and $5.13 \mathrm{kcal} / \mathrm{mol}$, respectively. The principal factors contributing to these energies are the electronic and steric effects of the two different substituents, the aryl group and the phosphine. The electronic effect would weaken the bond to the red oxygen to a greater extent than that to the black oxygen because of the greater kinetic trans effect ${ }^{59}$ of the aryl group compared to the phosphine, thus favoring 60-InterTS-TA. The steric contribution arises from interaction of the B-aryl group with those two substituents as it rotates toward the empty coordination site on the palladium in the transition state. Clearly, steric repulsion in 60-InterTS-TA is greater as the $\mathrm{B}$-aryl group becomes proximal to the bulky $i-\mathrm{Pr}_{3} \mathrm{P}$ ligand. Thus, the difference of $0.93 \mathrm{kcal} / \mathrm{mol}$ favoring $\mathbf{6 0}$-InterTS-TP suggests that the steric effect dominates in this process. ${ }^{60}$ In fact, the dominance of this steric repulsion can be seen in the lower energy for all of the transition states and intermediates in the $T P$ compared to the $T A$ series.

In the critical transmetalation event, the activation energies for the B-aryl transfer for 60 - TS$T A$ and $60-T S-T P$ are 25.06 and $15.38 \mathrm{kcal} / \mathrm{mol}$, respectively, reflecting a remarkable activation energy difference of $9.7 \mathrm{kcal} / \mathrm{mol}$. The greater activation barrier to B-aryl migration for $60-T S$-TA can be attributed to the significant steric congestion around the palladium atom caused by the presence of the bulky $i-\operatorname{Pr}_{3} \mathrm{P}$ group, whereas migration of the $\mathrm{B}$-aryl group to the empty coordination site in $60-T S$ - $T P$ is free of such repulsions and thus is energetically more favorable (Figure 10). These energetic differences are reflected in bonding distances between the palladium atom and the ipso carbon of the migrating aryl group, as shown in Figure 10. An additional electronic contribution comes from migration of the B-aryl group to the site opposite to the substituent with the stronger trans effect in $\mathbf{6 0}$ $T S$-TA, thus constituting a kinetic deterrent. The activation barrier for the transmetalation transition state $60-T S-T P(15.38 \mathrm{kcal} / \mathrm{mol})$ is consistent with the experimentally measured value of $17.7 \pm 1 \mathrm{kcal} / \mathrm{mol}$ (Table 2$){ }^{61}$

After the transmetalation event, the immediate product is either $\mathbf{6 0}$-Prod-Trans or $\mathbf{6 0 - P r o d -}$ Cis diarylpalladium complex with the coordinated $\mathrm{B}(\mathrm{OH})_{3}$ trans to $i-\mathrm{Pr}_{3} \mathrm{P}$ or the 4fluorophenyl group. The reductive elimination is presumably initiated by the dissociation of boric acid, thus generating the active tri-coordinate diarylpalladium complexes which are poised to form cross-coupling products. ${ }^{62}$

3.3.2. Computational Analysis of Complex 61.-The energy surface calculated for the 6-B-3 complex $\mathbf{6 1}$ is shown in Figure 11. Inspection of the energy profile reveals that the ground states 61-React-TP and 61-React-TA differ by $0.99 \mathrm{kcal} / \mathrm{mol}$. The energies of transition states 61-InterTS-TA and 61-InterTS-TP for the formation for the two different T- 
shaped complexes are 7.62 and $7.92 \mathrm{kcal} / \mathrm{mol}$, respectively. The difference of $0.3 \mathrm{kcal} / \mathrm{mol}$ favoring 61-InterTS-TA indicates that the kinetic trans effect $^{59}$ of the aryl group is now dominant compared to the steric repulsion engendered by the $i-\mathrm{Pr}_{3} \mathrm{P}$ ligand. ${ }^{63}$ However, in all succeeding steps on the energy profile, the structures in the $T A$ family are of significantly higher energy than those in the $T P$ family. This behavior can be understood in terms of the same steric and electronic influences as were seen in the 8-B-4 transition-state structures (Figure 11). After the transmetalation event, the diarylpalladium complexes (61-Prod-Cis, 61-Prod-Trans) are only $0.78-1.13 \mathrm{kcal} / \mathrm{mol}$ downhill, thus indicating very late transition states.

The existence of late transition states is clearly signaled by the small difference in lengths of the forming bonds between the ipso carbon on the migrating group and the palladium atom for both 61-TS-TP (2.085 $⿱$ ) and 61-TS-TA (2.171 $\mathrm{A})$ compared to 61-Prod-Cis (2.069 $)$ and 61-Prod-Trans (2.154 $\AA$ ), respectively. In this series the bonds are shortened by only 0.016-0.017 $\AA$, whereas in the 8-B-4 series the corresponding changes for 60-TS-TP $(2.199$ $\AA$ ) and 60-TS-TA (2.285 $\AA$ ) compared to 60-Prod-Cis $(2.046 \AA)$ and 60-Prod-Trans (2.103 $\AA)$ are much larger (0.153-0.182 ̊, Figures 10 and 12).

The subsequent reductive elimination is presumably initiated by the dissociation of the boron species to form free diarylpalladium complexes (Pd-Prod-Cis, Pd-Prod-Trans). However, the computational modeling of this event leads to a prohibitively endergonic process, which is most likely ascribable to the high energy of the $\mathrm{O}=\mathrm{B}(\mathrm{OH})$ moiety. To solve this problem, we assume that some kind of bimolecular oligomerization takes place to remove $\mathrm{O}=\mathrm{B}(\mathrm{OH})$ as a byproduct. Thus, to calculate the energies of the final reductive elimination products, instead of directly using the energy of $\mathrm{O}=\mathrm{B}(\mathrm{OH})$, one-third energy of the $\mathrm{O}=\mathrm{B}(\mathrm{OH})$ trimer, metaboric acid, was computed and added to the tri-coordinate diarylpalladium complexes, which in turn gives reasonable energies to both Pd-Prod-Trans $(1.42 \mathrm{kcal} / \mathrm{mol})$ and Pd-Prod-Cis $(-10.31 \mathrm{kcal} / \mathrm{mol}){ }^{64}$

\section{CONCLUSIONS}

The combination of low-temperature and rapid injection NMR spectroscopic analysis has allowed the unambiguous demonstration that $\mathrm{Pd}-\mathrm{O}-\mathrm{B}$ linkages form prior to the transmetalation event in the Suzuki-Miyaura cross-coupling reaction. Structures of the intermediates identified were assigned by NMR spectroscopy, with the NOE and HMBC experiments being crucial in determining the bonding connectivity. These structural assignments were supported by independent synthesis, which clearly demonstrated that, under certain reaction conditions, both Path A and Path B can lead to pre-transmetalation intermediates. The ability to form $\mathrm{Pd}-\mathrm{O}-\mathrm{B}$ linkages provided the unprecedented opportunity to probe the effect of the phosphine ligand on both structure and reactivity. Furthermore, a series of structural, kinetic, and computational investigations revealed two mechanistically distinct pathways: (1) transmetalation via a 6-B-3 intermediate that dominates in the presence of excess phosphine, and (2) transmetalation via an anionic 8-B-4 intermediate that dominates in mono-ligated or cis-chelated systems. The observation of direct transmetalation from a tri-coordinate boron center (complex 51) challenges the current dogma that boron must be activated by base prior to transmetalation. Overall, the key feature 
that enables the transfer of the organic fragment from boron to palladium is the availability of an empty coordination site on the palladium atom. The importance of a coordinatively unsaturated palladium atom was revealed by both the inverse first-order dependence on $i$ $\mathrm{Pr}_{3} \mathrm{P}$ and inhibitory effects of water for the formation of cross-coupling product from the 6B-3 intermediate 51. The importance of a sub-ligated palladium atom was further demonstrated by the DFT calculations and rapid transmetalation observed in 8-B-4 complex 60 that contained a single $i-\mathrm{Pr}_{3} \mathrm{P}$ ligand bound to palladium. Further effects of solvent, boron sources, and additives on the transmetalation event are currently under investigation and will be reported in due course.

\section{Supplementary Material}

Refer to Web version on PubMed Central for supplementary material.

\section{ACKNOWLEDGMENTS}

We are grateful for generous financial support from the National Science Foundation (CHE1012663 and CHE1151566). A.A.T. is grateful to the University of Illinois and Eli Lilly for Graduate Fellowships. Dr. Lingyang Zhu is thanked for helpful suggestions on NMR spectroscopy. Some of this data was collected in the Core Facilities at the Carl R. Woese Institute for Genomic Biology on a $600 \mathrm{MHz}$ NMR funded by NIH grant number S10RR028833 and the Integrated Molecular Structure Education and Research Center at Northwestern University.

\section{REFERENCES}

(1). (a)Chemla F; Ferreira F; Perez-Luna A; Micouin L; Jackowski O In Metal-Catalyzed CrossCoupling Reactions and More, 3rd ed.; Meijere A, Brase S, Oestreich M, Eds.; Wiley-VCH: Weinheim, Germany, 2014; Vol. 1, Chapter 5.(b)Heravi MM; Hajiabbasi P Monatsh. Chem 2012, $143,1575-1592$.

(2). (a)Lee JCH; Hall DG In Metal-Catalyzed Cross-Coupling Reactions and More, 3rd ed.; de Meijere A, Bräse S, Oestreich M, Eds.; Wiley-VCH: Weinheim, Germany, 2014; Vol. 1 Chapter 2. (b)Lennox AJJ; Lloyd-Jones GC Chem. Soc. Rev 2014, 43, 412-443. [PubMed: 24091429] (c)Miyaura N; Suzuki A Chem. Rev 1995, 95, 2457-2483.

(3). (a)Martín-Matute B; Szabó KJ; Mitchell TN In Metal-Harrison NL; Hughes DL; Schubert CJ; Sutton BM; Watts, Catalyzed Cross-Coupling Reactions and More, 3rd ed.; de Meijere A, Bräse S, Oestreich M, Eds.; Wiley-VCH: Weinheim, Germany, 2014; Vol. 2, Chapter 6.(b)Farina V; Krishnamurthy V; Scott WJ Org. React 1997, 50, 1.

(4). (a)Chang WTT; Smith RC; Regens CS; Bailey AD; Werner NS; Denmark SE Org. React. 2011, 75, 213.(b)Denmark SE; Sweis RF In Metal-Catalyzed Cross-Coupling Reactions and More, 3rd ed.; de Meijere A, Bräse S, Oestreich M, Eds.; Wiley-VCH: Weinheim, Germany, 2014; Vol. 2, Chapter 7.

(5). (a)Xu S; Kamada H; Kim EH; Oda A; Negishi E In Metal-Catalyzed Cross-Coupling Reactions and More, 3rd ed.; de Meijere A, Bräse S, Oestreich M, Eds.; Wiley-VCH: Weinheim, Germany, 2014; Vol. 1, Chapter 3.(b)Phapale VB; Cardenas DJ Chem. Soc. Rev. 2009, 38, 1598-1607. [PubMed: 19587955]

(6). (a)Suzuki A Angew. Chem., Int. Ed 2011, 50, 6722-6737.(b)Seechurn CCCJ; Kitching MO; Colacot TJ; Snieckus V Angew. Chem., Int. Ed 2012, 51, 5062-5085.

(7). Picquet M In Organometallics as Catalysts in the Fine Chemical Industry; Matthias B, Blaser HU, Eds.; Springer: Berlin/Heidelberg, 2013; Vol. 42, Chapter 1.

(8). (a)Magano J; Dunetz JR Chem. Rev 2011, 111, 2177-2250. [PubMed: 21391570] (b)Torborg C; Beller M Adv. Synth. Catal 2009, 351, 3027-3043.(c)Corbet J-P; Mignani G Chem. Rev 2006, 106, 2651-2710. [PubMed: 16836296] (d)Lipton MF; Mauragis MA; Maloney MT; Veley MF; VanderBor DW; Newby JJ; Appell RB; Daugs ED Org. Process Res. Dev 2003, 7, 385-392. 
(9). (a)For leading texts on this subject, see: Labinger JA Organometallics 2015, 34, 4784-4795. (b)Hartwig JF Organotransition Metal Chemistry: From Bonding to Catalysis; University Science Books: Sausalito, CA, 2010.(c)Collman JP; Hegedus LS Principles and Applications of Organotransition Metal Chemistry; University Science Books: Mill Valley, CA, 1980.

(10). (a)Hartwig JF Inorg. Chem 2007, 46, 1936-1947. [PubMed: 17348724] (b)Procelewska J; Zahl A; Liehr G; van Eldik R; Smythe NA; Williams BS; Goldberg KL Inorg. Chem 2005, 44, 7732 7742. [PubMed: 16241122] (c)Shekhar S; Hartwig JF J. Am. Chem. Soc 2004, 126, 1301613027. [PubMed: 15469300] (d)Hartwig JF Acc. Chem. Res 1998, 31, 852-860.(e)Komiya S; Albright TA; Hoffmann R; Kochi JK J. Am. Chem. Soc 1976, 98, 7255-7265.

(11). Labadie JW; Stille JK J. Am. Chem. Soc 1983, 105, 6129-6137.

(12). (a)Tymonko SA; Smith RC; Ambrosi A; Denmark SE J. Am. Chem. Soc. 2015, 137, 6192-9199. [PubMed: 25945390] (b)Tymonko SA; Smith RC; Ambrosi A; Ober MH; Wang H; Denmark SE J. Am. Chem. Soc 2015, 137, 6200-6218. [PubMed: 25945516]

(13). (a)Schmidt AF; Kurokhtina AA; Smirnov VV; Larina EV; Chechil EV Kinet. Catal 2012, 53, 214-221.(b)Zim D; Lando VR; Dupont J; Monteiro AL Org. Lett 2001, 3, 3049-3051. [PubMed: 11554840] (c)Moreno-Mañas M; Perez M; Pleixats RJ Org. Chem 1996, 61, 2346-2351.

(14). For an excellent summary of the current state of understanding of transmetalation in the SuzukiMiyaura reaction, see: Lennox AJJ; Lloyd-Jones GC Angew. Chem., Int. Ed 2013, 52, 73627370.

(15). (a)Strictly speaking, other transmetalation pathways are possible with organoboron derivatives that do not require pre-association: Ohmura T; Awano T; Suginome M J. Am. Chem. Soc 2010, 132, 13191-13193. [PubMed: 20822146] (b)Sandrock D; Jean-Gerard L; Chen CY; Dreher SD; Molander GA J. Am. Chem. Soc 2010, 132, 17108-17110. [PubMed: 21077687] (c)Lee JCH; McDonald R; Hall DG Nat. Chem 2011, 3, 894-899. [PubMed: 22024887]

(16). (a)Miyaura N; Yamada K; Suzuki A Tetrahedron Lett 1979, 20, 3437-3440.(b)Miyaura N; Suzuki AJ Chem. Soc., Chem. Commun 1979, 866-867.

(17). The use of pre-formed tetracoordinate metal boronates as cross-coupling partners has gained much attention over the past decade due to the ease of their preparation and isolation. The advantage of using pre-formed metal trihydroxyborates $\mathrm{RB}(\mathrm{OH}) 3-$ is that no additional base is necessary: Cammidge AN; Goddard VHM; Gopee H; Harrison NL; Hughes DL; Schubert CJ; Sutton BM; Watts GL; Whitehead A Org. Lett 2006, 8, 4071-4074. [PubMed: 16928076]

(18). Miyaura N; Yamada K; Suginome H; Suzuki AJ Am. Chem. Soc 1985, 107, 972-980.

(19). Matos K; Soderquist JA J. Org. Chem 1998, 63, 461-470. [PubMed: 11672034]

(20). Ortuño MA; Lledós A; Maseras F; Ujaque G ChemCatChem 2014, 6, 3132-3138.

(21). (a)These conclusions have also been reached in similar DFT investigations: Sicre C; Braga AAC; Maseras F; Cid MM Tetrahedron 2008, 64, 7437-7443.(b)Sumimoto M; Iwane N; Takahama T; Sakaki SJ Am. Chem. Soc 2004, 126, 10457-10471.(c)Goossen LJ; Koley D; Hermann HJ; Thiel WJ Am. Chem. Soc 2005, 127, 11102-11114.(d)Goossen LJ; Koley D; Hermann HL; Thiel W Organometallics 2006, 25, 54-67.

(22). Jover J; Fey N; Purdie M; Lloyd-Jones GC; Harvey JNJ Mol. Catal. A: Chem 2010, 324, 39-47.

(23). Carrow BP; Hartwig JF J. Am. Chem. Soc 2011, 133, 2116-2119. [PubMed: 21280669]

(24). (a)Amatore C; Jutand A; Le Duc G Chem. - Eur. J 2011, 17, 2492-2503. [PubMed: 21319240] (b)Amatore C; Jutand A; Le Duc G Angew. Chem 2012, 124, 1408-1411.

(25). Schmidt AF; Kurokhtina AA; Larina EV Russ. J. Gen. Chem 2011, 81, 1573-1574.

(26). $\left(\mathrm{Ph}_{3} \mathrm{P}\right)_{2} \mathrm{PdPhOH}$ was generated in situ by reacting $\left[\left(\mathrm{Ph}_{3} \mathrm{P}\right) \mathrm{PdPh}(\mathrm{OH})\right]_{2}$ in the presence of excess $\mathrm{Ph}_{3} \mathrm{P}$.

(27). Aliprantis AO; Canary JW J. Am. Chem. Soc. 1994, 116, 6985-6986.

(28). Pantcheva I; Nishihara Y; Osakada K Organometallics 2005, 24, 3815-3817.

(29). Zhao P; Incarvito CD; Hartwig JF J. Am. Chem. Soc 2007, 129, 1876-1877. [PubMed: 17256944]

(30). (a)Denmark SE; Williams BJ; Eklov BM; Pham SM; Beutner GL J. Org. Chem 2010, 75, 55585572. [PubMed: 20672809] (b)Bartholomew ER; Bertz SH; Cope SK; Murphy MD; Ogle CA; Thomas AA Chem. Commun. 2010, 46, 1253-1254. 
(31). McGarrity JF; Prodolliet J; Smyth T Org. Magn. Reson. 1981, 17, 59-65.

(32). A preliminary communication describing some of these results has already appeared: Thomas AA; Denmark SE Science 2016, 352, 329-332. [PubMed: 27081068]

(33). Butters M; Harvey JN; Jover J; Lennox AJJ; Lloyd-Jones GC; Murray PM Angew. Chem., Int. Ed 2010, 49, 5156-5160.

(34). For a complete, tabular listing of all chemical shifts, see the Supporting Information.

(35). Grushin VV; Alper H Organometallics 1996, 15, 5242-5245.

(36). In the absence of excess $i$ - $\operatorname{Pr}_{3} \mathrm{P}$, the cross-coupling product 53 was observed.

(37). Nishihara Y; Onodera H; Osakada K Chem. Commun 2004, 192-193.

(38). This classification designates $N$-X-L species where $N$ is the number of formally valence-shell electrons about atom X, involved in bonding L ligands to X: Perkins CW; Martin JC; Arduengo AJ; Lau W; Alegria A; Kochi JK J. Am. Chem. Soc 1980, 102, 7753-7759.

(39). Weber E; Skobridis K; Ouchi M; Hakushi T; Inoue Y Bull. Chem. Soc. Jpn. 1990, 63, 36703677.

(40). Driver MS; Hartwig JF Organometallics 1997, 16, 5706-5715.

(41). Complex 62 exists as a mixture of cis and trans dimers as observed by Grushin (see ref 35).

(42). For related 2:1 palladium complexes with acetate ligands, see: Stephenson TA; Morehouse SM Mrs.; Powell AR; Heffer JP; Wilkinson G J. Chem. Soc 1965, 3632-3640.

(43). To confirm the conclusion of a direct displacement of halide from $\mathbf{6 4}$ with $\mathbf{5 6}$, a control experiment was performed by combining 62 with 56 at $-50{ }^{\circ} \mathrm{C}$ for $1 \mathrm{~h}$, whereupon only trace conversion $(<5 \%)$ was observed by ${ }^{19} \mathrm{~F}$ and ${ }^{31} \mathrm{P}$ NMR spectroscopy.

(44). See Supporting Information for details.

(45). Methanol was chosen over water due to the low temperatures needed for intermediate formation. Characterization experiments were performed using THF- $d_{8}$ mixed with either $\mathrm{CH}_{3} \mathrm{OH}$ or $\mathrm{CD}_{3} \mathrm{OD}$.

(46). Addition of methanol ( $60 \mu \mathrm{L})$ to a THF solution of complex 63 at $-78{ }^{\circ} \mathrm{C}$ followed by warming to $-60{ }^{\circ} \mathrm{C}$ resulted in a quantitative conversion to both 68 and 62 in a ratio of 1:0.5, indicating that $\mathrm{Pd}-(\mu-\mathrm{OH})-\mathrm{Pd}$ is not broken by methanol.

(47). A solution of arylboronic acid 47 in $\mathrm{THF} / \mathrm{CH}_{3} \mathrm{OH}$ (10:1) displays a ${ }^{11} \mathrm{~B}$ NMR signal at $30 \mathrm{ppm}$, indicating that methanol is not sufficiently Lewis basic to coordinate to the boron atom.

(48). Brown HC J. Am. Chem. Soc 1945, 67, 374-378.

(49). Hayashi Y; Wada S; Yamashita M; Nozaki K Organometallics 2012, 31, 1073-1081.

(50). Schott D; Pregosin PS; Veiros L; Calhorda MJ Organometallics 2005, 24, 5710-5717.

(51). The lack of a measurable ${ }^{11} \mathrm{~B}$ NMR chemical shift prohibits the unambiguous determination of a tri- or tetracoordinate boron atom.

(52). As described in section 3.1.7, it is not possible to confirm this assertion spectroscopically because of the rapid exchange among 47,60 , and 63 at $-30{ }^{\circ} \mathrm{C}$ and the resulting coincidence of their NMR signals.

(53). Although complex 60 could not be characterized spectroscopically, in section 3.2.1, it was demonstrated to be the active transmetalating species in pure THF. Therefore, the identity of $\mathrm{Ph}_{3} \mathrm{P}$ complex $\mathbf{7 3}$ is inferred on the basis of the observation of similar reactivity in THF.

(54). This conclusion is supported by the observation of a positive rho value for a Hammett study on the transmetalation step in the related cross-coupling of arylsilanolates. See: Denmark SE; Smith RC; Chang W-TT Tetrahedron 2011, 67, 4391-4396. [PubMed: 21731114]

(55). Schmid R; Sapunov VN In Non-Formal Kinetics in Search for Chemical Reaction Pathways; Ebel HF, Ed.; Verlag Chemie:Weinheim, 1982; Vol. 14, Chapter 3.

(56). Kuran W; Musco A Inorg. Chim. Acta 1975, 12, 187-193.

(57). The complexity of the autocatalytic system lends itself to other possible interpretations. We offer an explanation that is most consistent with all of the available data, but we cannot unambiguously exclude the possibility that, in the presence of water, the transmetalation may still be proceeding through 8-B-4 species 60.

(58). In addition to $\mathbf{6 1}$, approximately $25 \%$ of cross-coupling product $\mathbf{5 3}$ was observed. 
(59). Appleton TG; Clark HC; Manzer LE Coord. Chem. Rev 1973, 10, 335-422.

(60). This energy difference is also reflected in the greater Pd-C(ipso)B bond distances in both $\mathbf{6 0}$ InterTS-TA and 60-Inter-TA (2.945 and 2.844 $\mathrm{A})$ compared to 60-InterTS-TP and 60-Inter-TP (2.647 and $2.418 \AA$ ).

(61). The enthalpic contributions to the transition-state energies is much closer, as shown in Table 1, and is a more reliable measure of the bonding contributions.

(62). Tatsumi K; Hoffmann R; Yamamoto A; Stille JK Bull. Chem. Soc. Jpn 1981, 54, 1857-1867.

(63). The switch in relative energies for the Pd-O bond-breaking transition states for $\mathbf{6 1}$ vs $\mathbf{6 0}$ is again clearly reflected in the Pd-C(ipso)B bond distances. The significantly greater distances in both 61-InterTS-TA and 61-InterTS-TP(3.929 and 3.689 $\AA$ ) compared to 60-InterTS-TA and 60InterTS-TP(2.945 and $2.647 \AA)$ support the conclusion that the steric contribution of the phosphine ligand is attenuated in the 61-InterTS structures.

(64). The same strategy was used in the computational analysis of cross-coupling of arylpalladium arylsilanolates to account for the high-energy dimethylsilanone species formed directly from transmetalation. ${ }^{12 \mathrm{~b}}$ 


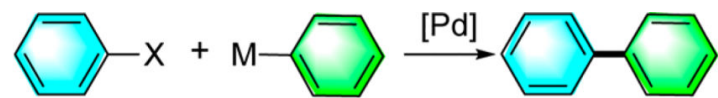

$\mathrm{M}=\mathrm{MgX}, \mathrm{BR}_{2}, \mathrm{SnR}_{3}, \mathrm{ZnX}, \mathrm{SiR}_{3}$

$\mathrm{X}=\mathrm{Cl}, \mathrm{Br}$, I, OTf, $\mathrm{N}_{2}^{+}$

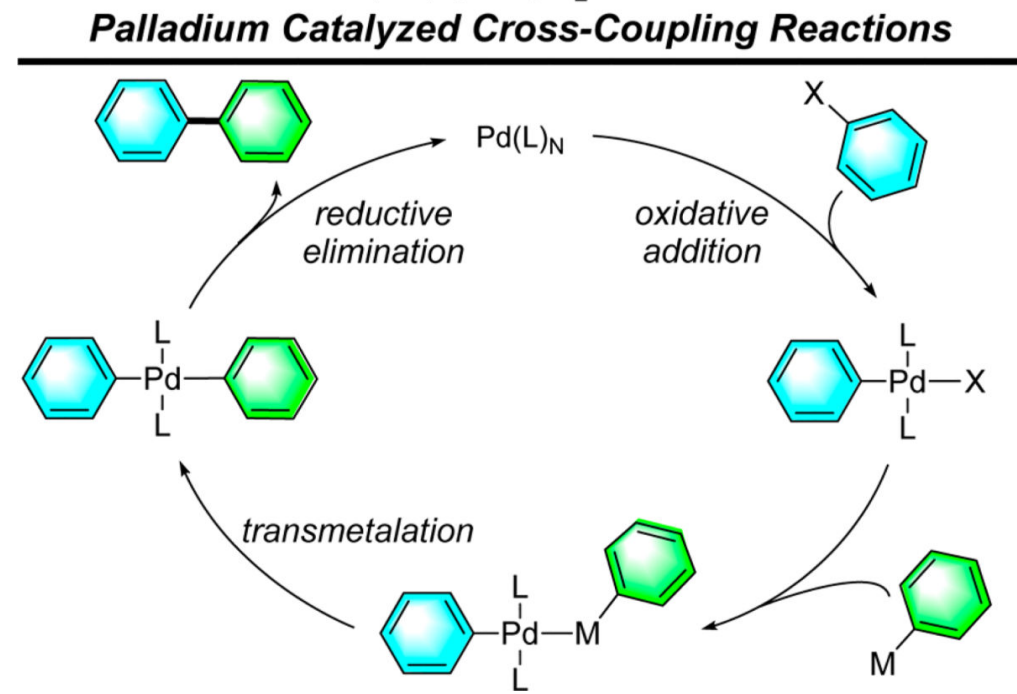

Figure 1.

Palladium-catalyzed cross-coupling reactions and general mechanism. 


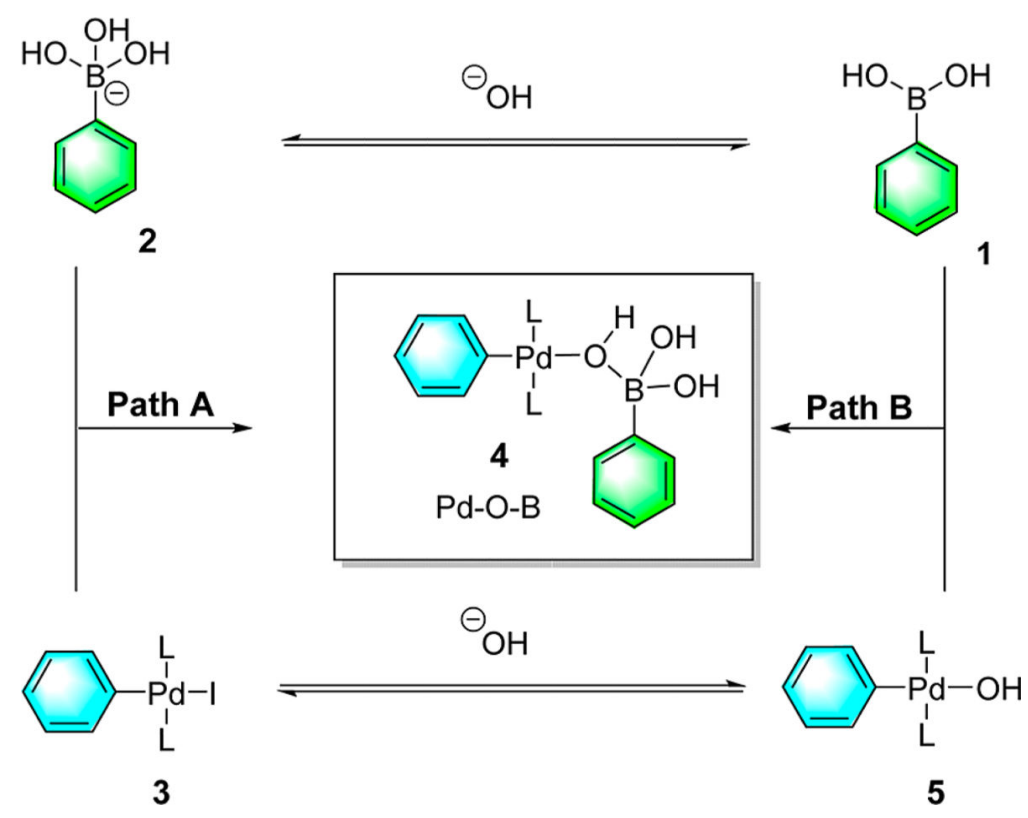

Figure 2.

Proposed transmetalation pathways in the Suzuki-Miyaura coupling process. 


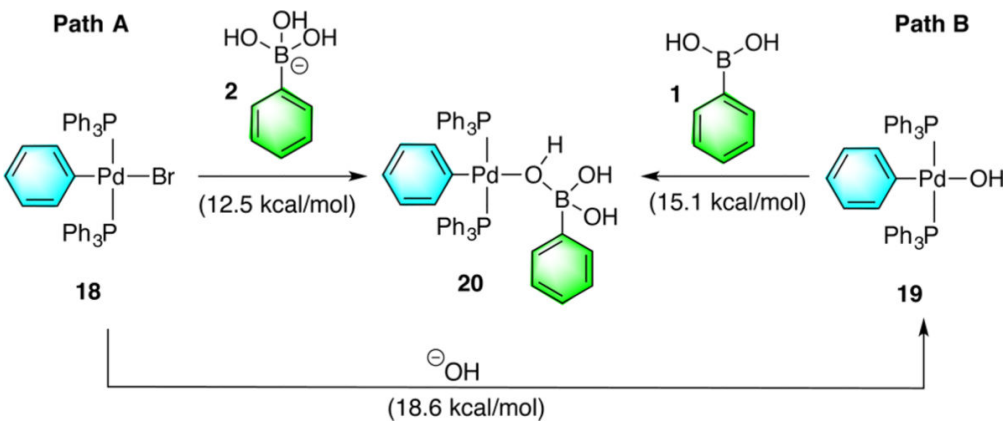

Figure 3.

DFT-calculated values for transmetalation. 

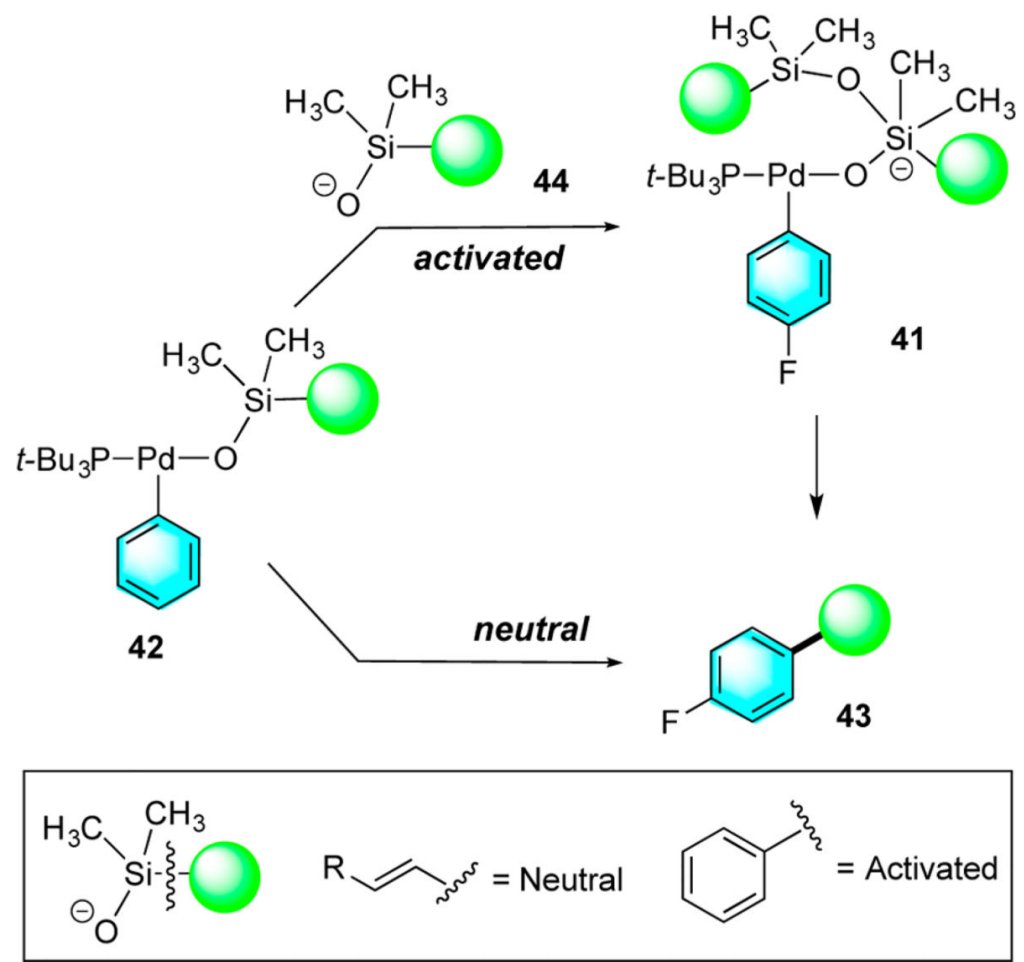

Figure 4.

Hiyama-Denmark transmetalation pathways. 


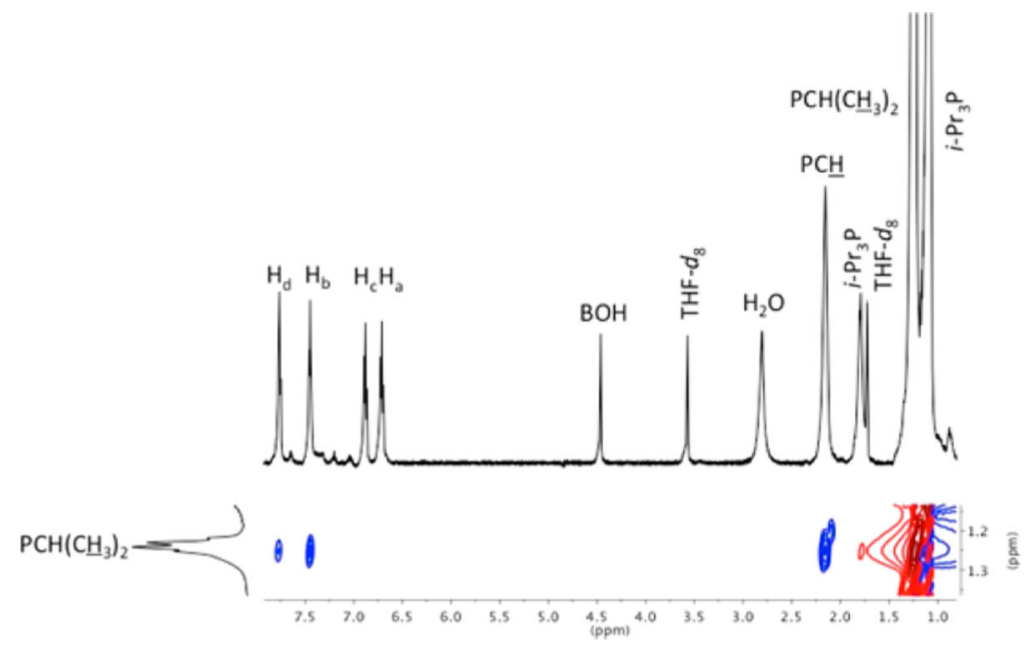

Figure 5.

NOESY spectrum of complex 51. 

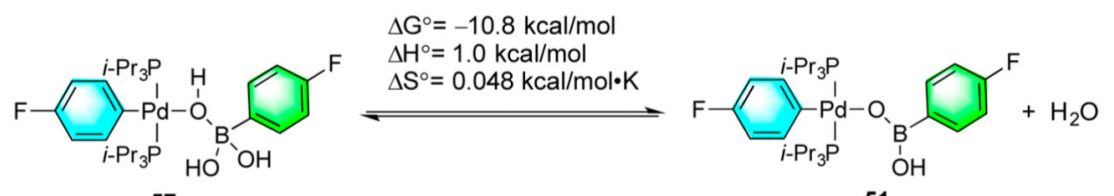

57
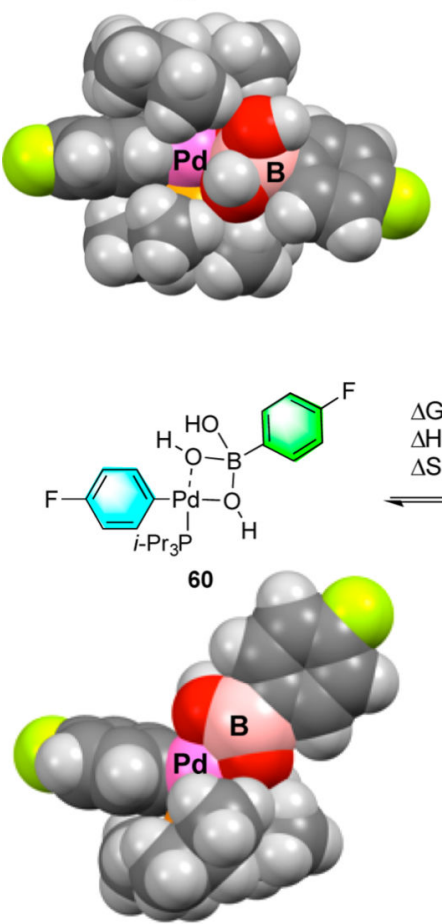
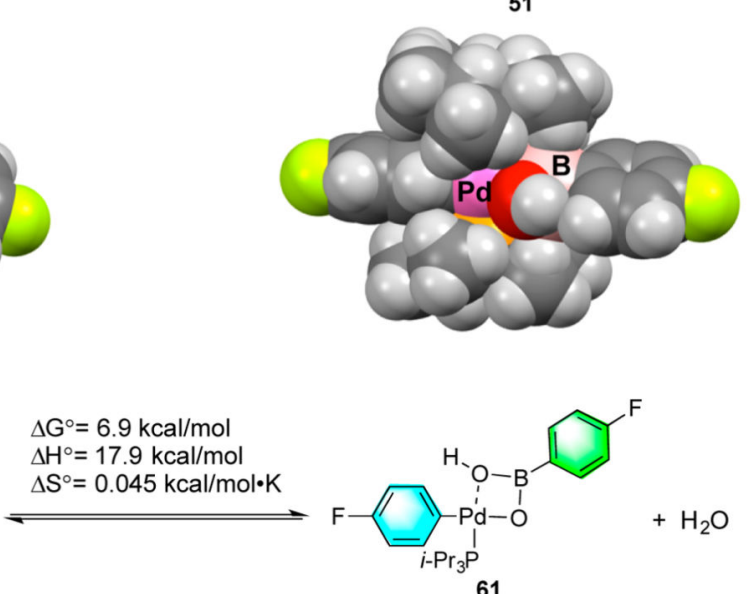

Figure 6.

Calculated equilibria for loss of water at $-30{ }^{\circ} \mathrm{C}$ from 8 -B-4 species $\mathbf{5 7}$ and $\mathbf{6 0}$. 


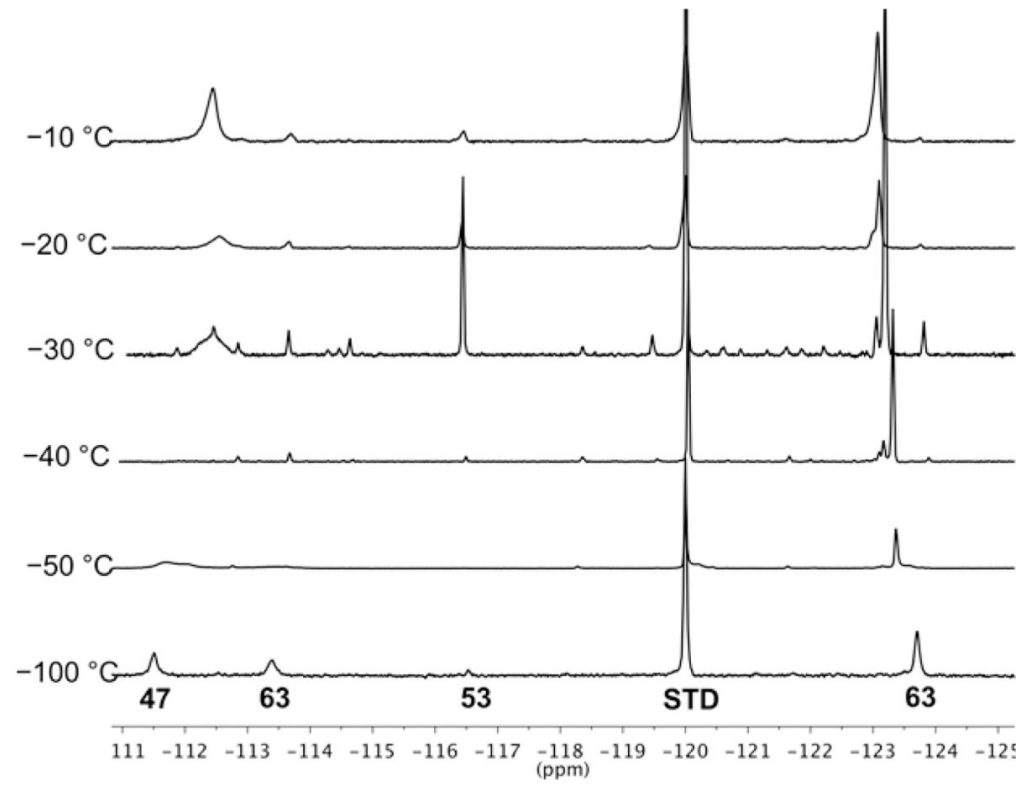

Figure 7.

Stacked plot of ${ }^{19} \mathrm{~F}$ NMR spectra recorded for a THF solution of 1.0 equiv of $\mathbf{4 7}$ and 1.0 equiv of 63 over a range of temperatures $\left(-100\right.$ to $\left.-10^{\circ} \mathrm{C}\right)$ at $565 \mathrm{MHz}$. 

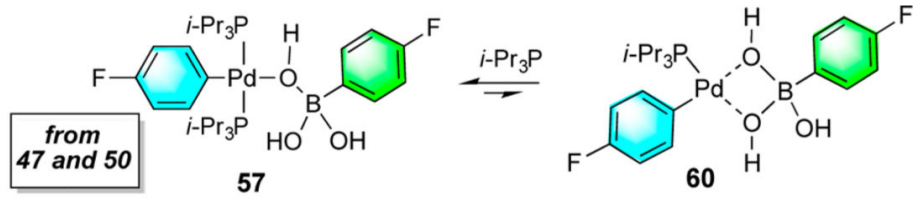

$\mid \mathrm{H}_{2} \mathrm{O}$

$\mathrm{H}_{2} \mathrm{O} \mid$
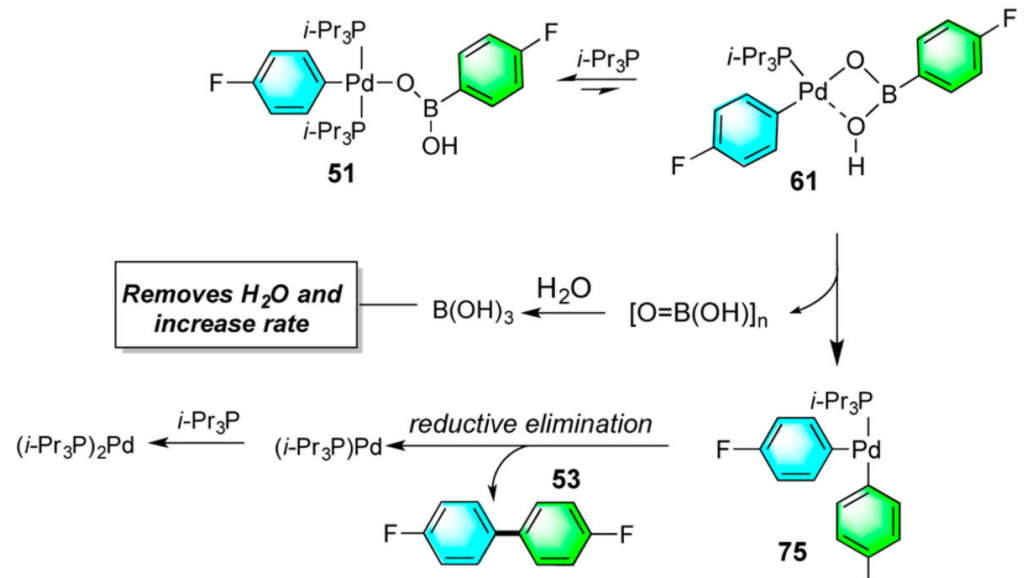

Figure 8.

Proposed mechanism for cross-coupling formation from 6-B-3 complex 51. 


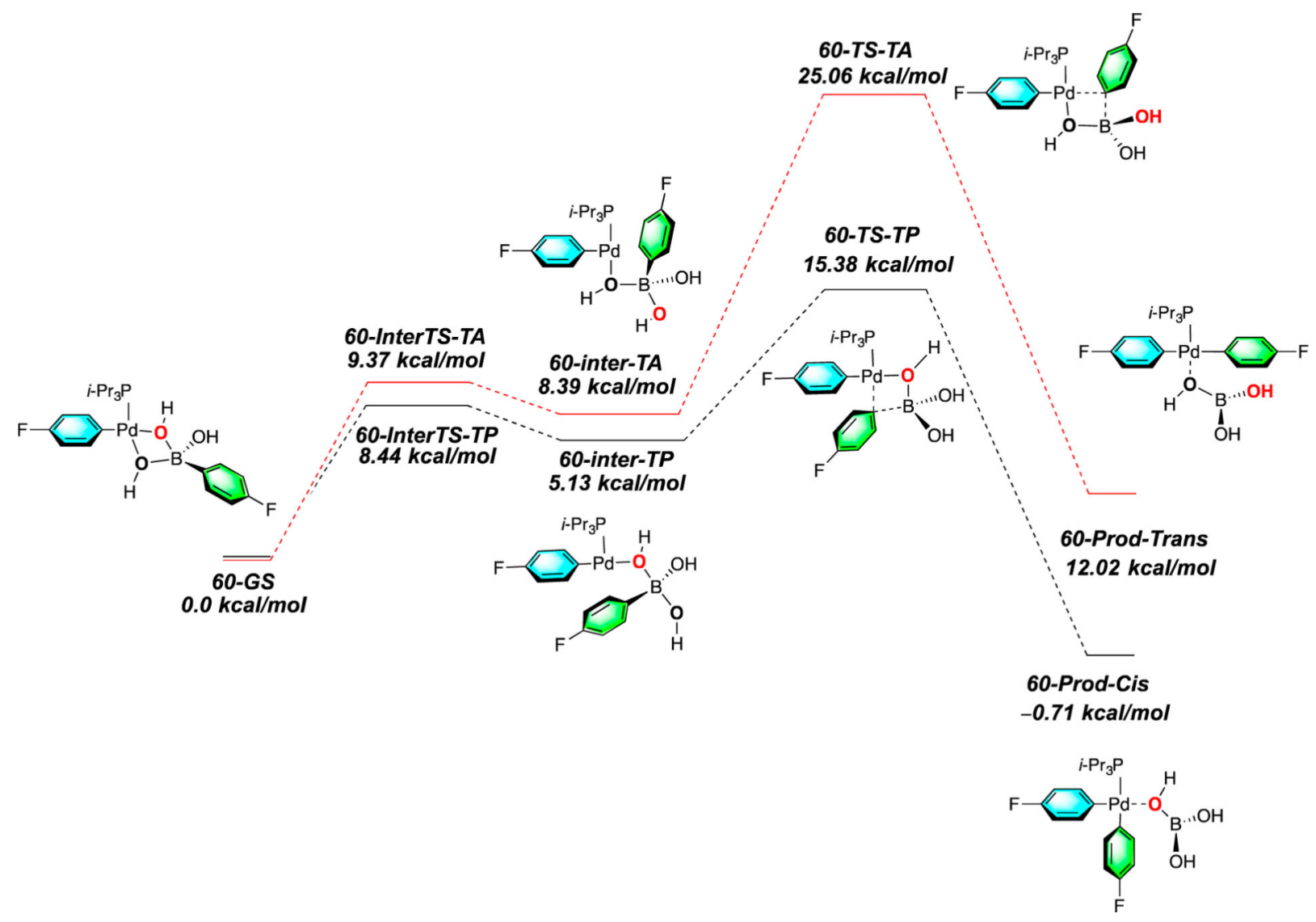

Figure 9.

Energy profile for the transmetalation of $\mathbf{6 0}$. Free energies are calculated using M062X/ LANL2DZ-6-31G(d) with CPCM solvation modeling (solvent = THF) for single-point energies with thermal corrections from B3LYP/LANL2DZ-6-31G(d) at $243.15 \mathrm{~K}$. 

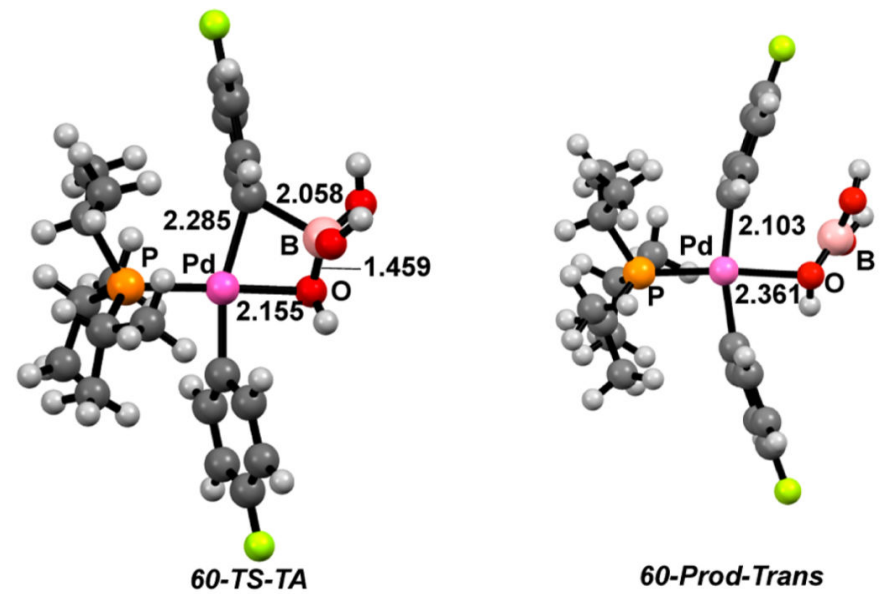

60-Prod-Trans
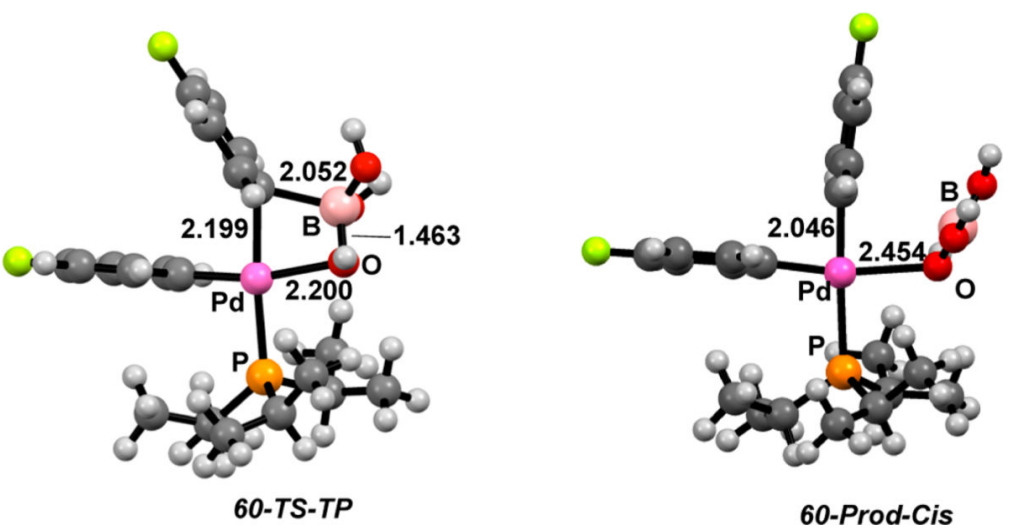

Figure 10.

Energy profile for the transmetalation of $\mathbf{6 0}$. Free energies are calculated using M062X/ LANL2DZ-6-31G(d) with CPCM solvation modeling (solvent = THF) for single-point energies with thermal corrections from B3LYP/LANL2DZ-6-31G(d) at 243.15 K. 


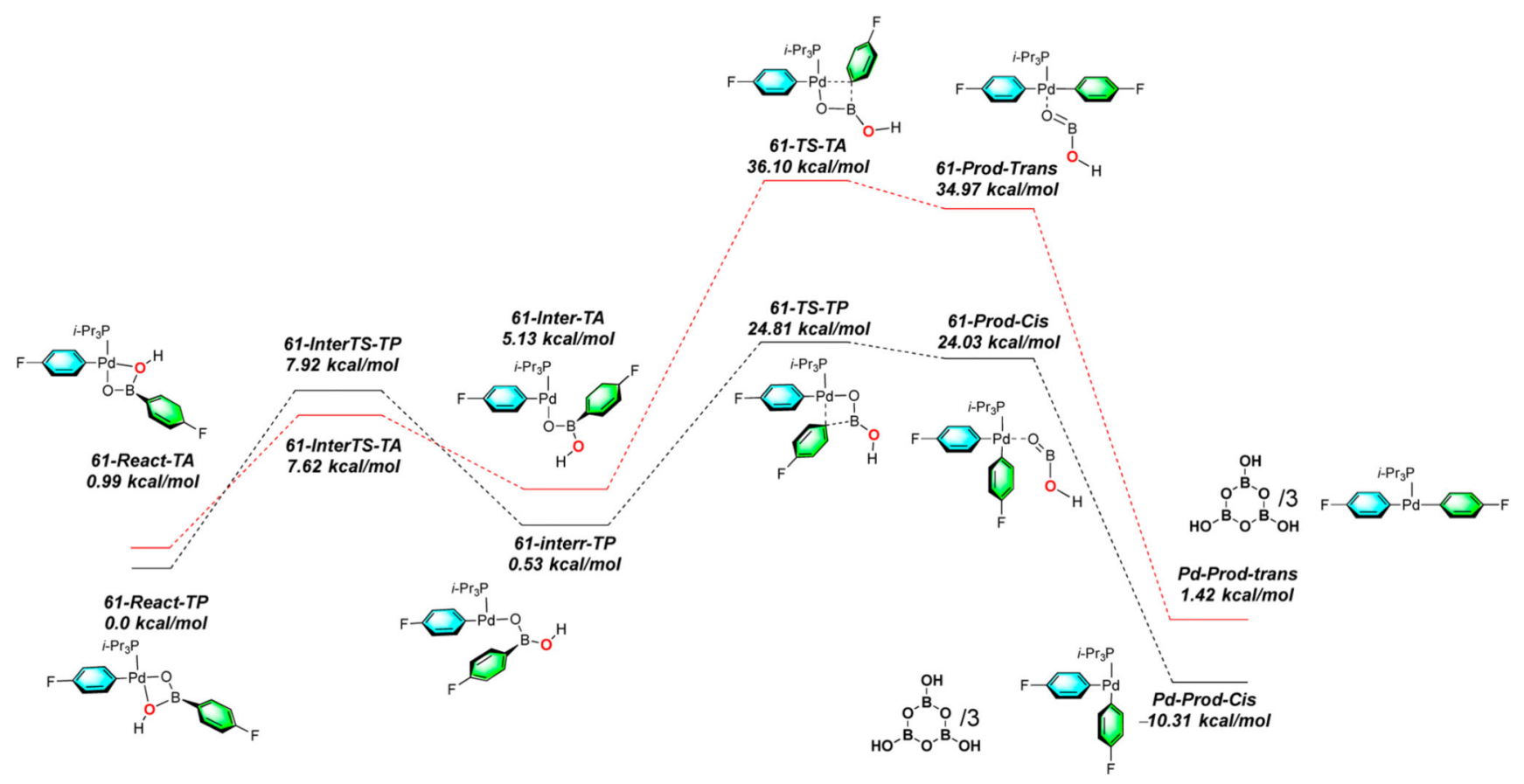

Figure 11.

Energy profile for the transmetalation of 6-B-3 species 61. Free energies are calculated using M062X/LANL2DZ-6-31G(d) with CPCM solvation modeling (solvent $=$ THF) for singlepoint energies with thermal corrections from B3LYP/LANL2DZ-6-31G(d) at $243.15 \mathrm{~K}$. 

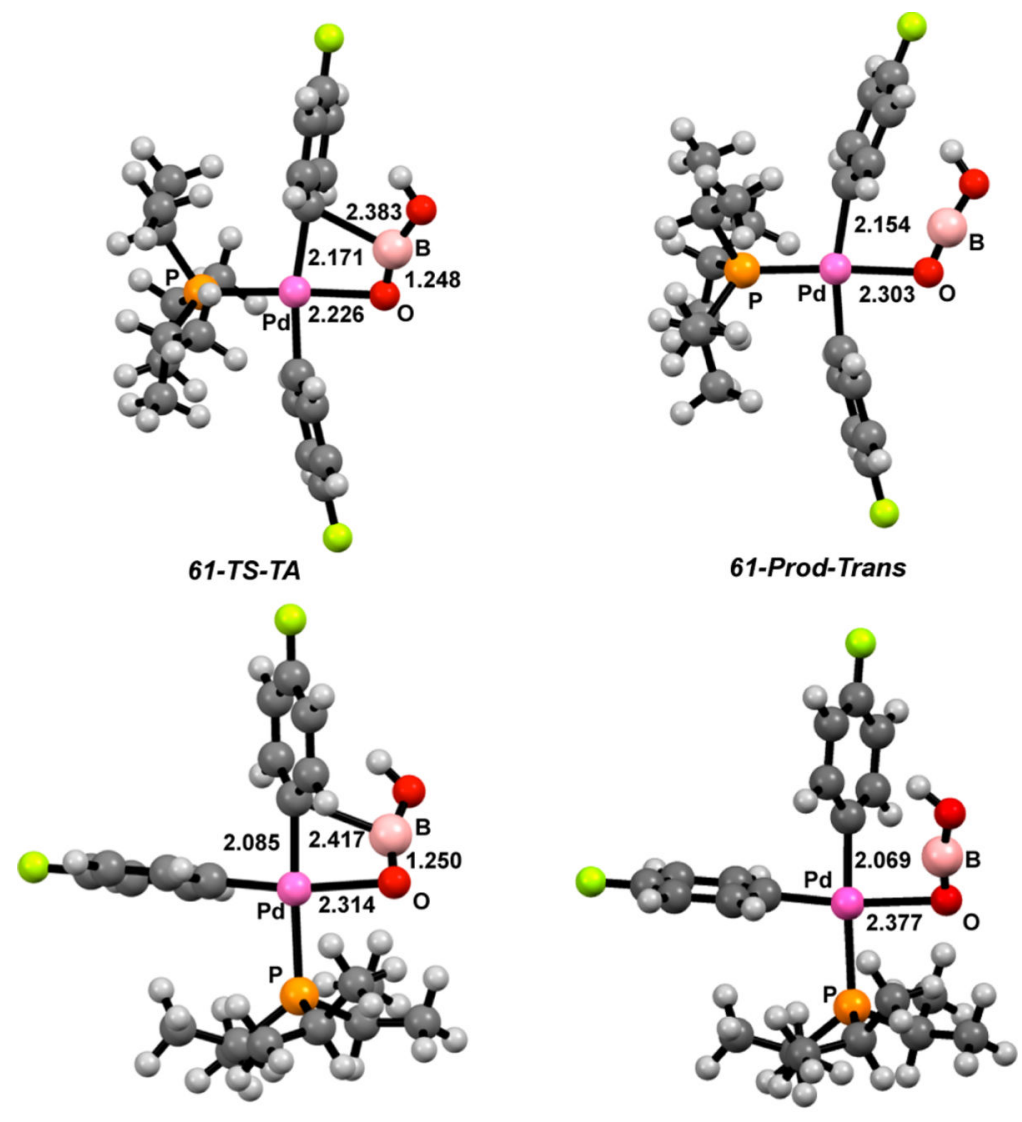

61-TS-TP

61-Prod-Cis

Figure 12.

Transition-state and complexed product structures for transmetalation of 61. Free energies are calculated using M062X/LANL2DZ-6-31G(d) with CPCM solvation modeling (solvent $=$ THF) for single-point energies with thermal corrections from B3LYP/ LANL2DZ-6-31G(d) at $243.15 \mathrm{~K}$. 


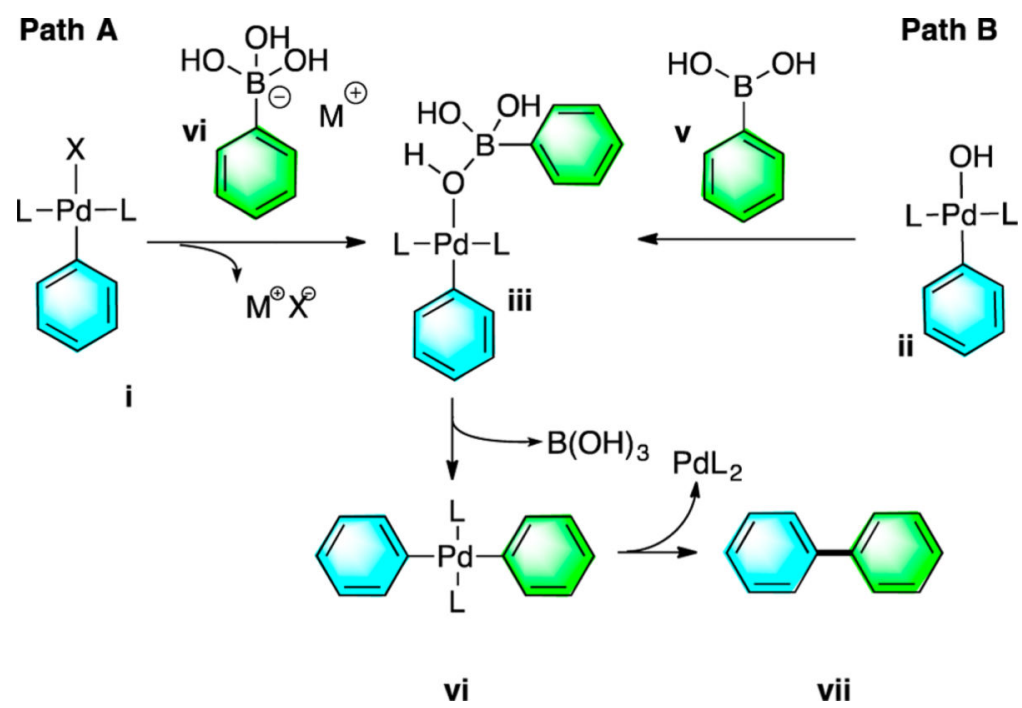

Path B

Scheme 1. 
$\mathrm{Bu}$<smiles>CC=CB1Oc2ccccc2[OH+]1</smiles>

6<smiles>Br/C=C/c1ccccc1</smiles>
THF, $2 \mathrm{~h}$

Scheme 2. 


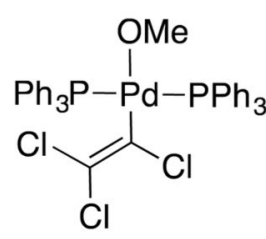

9

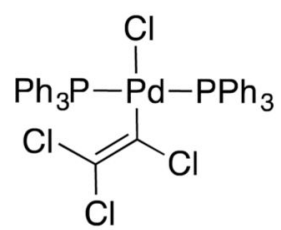

12

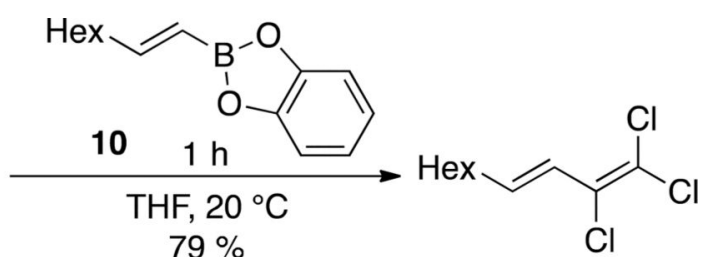

11

Scheme 3.

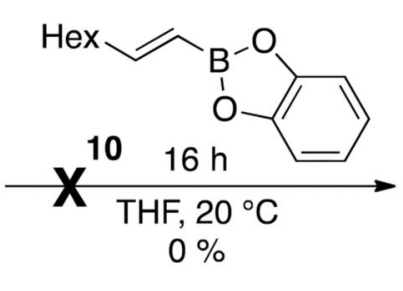

No Reaction 

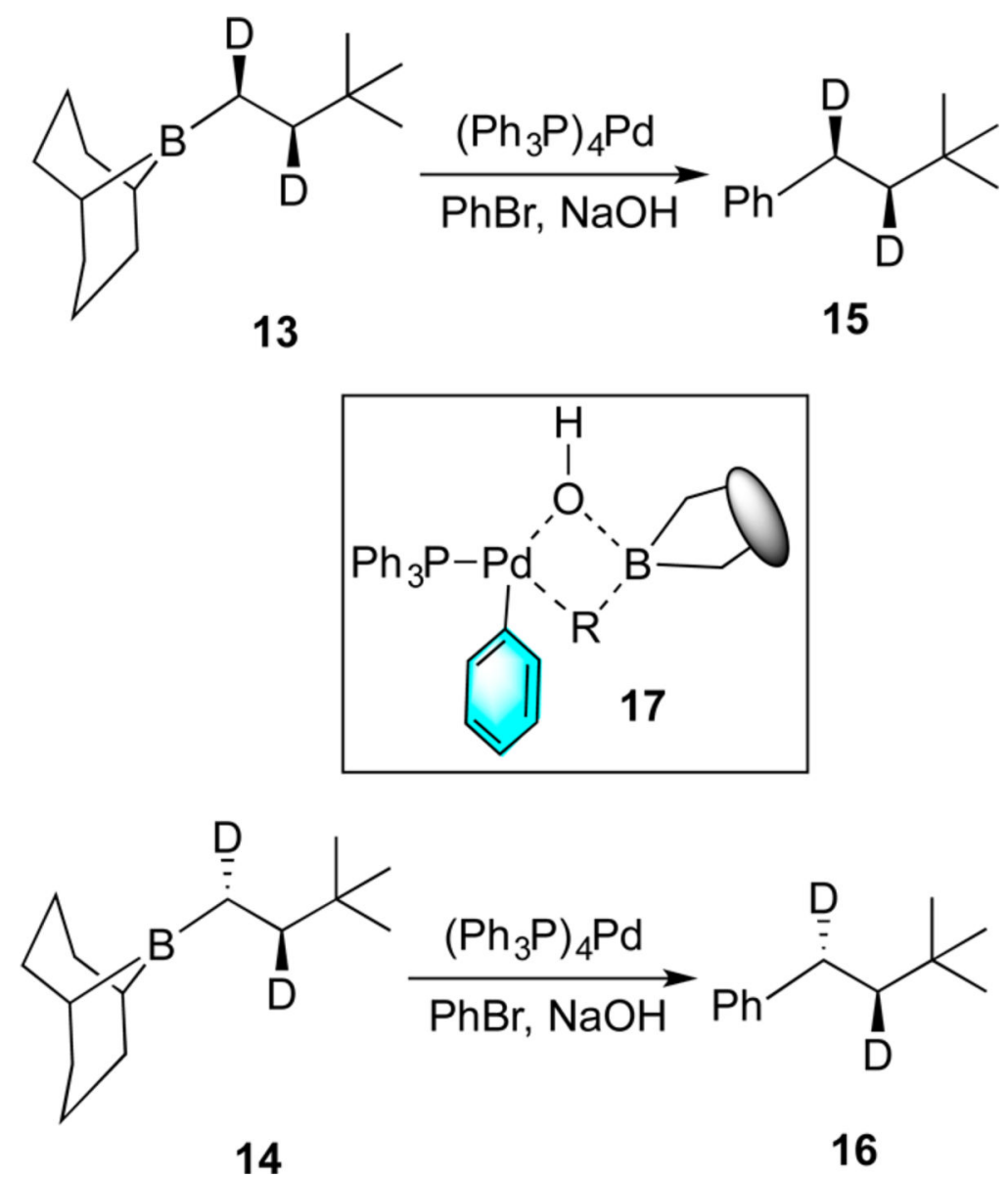

Scheme 4. 


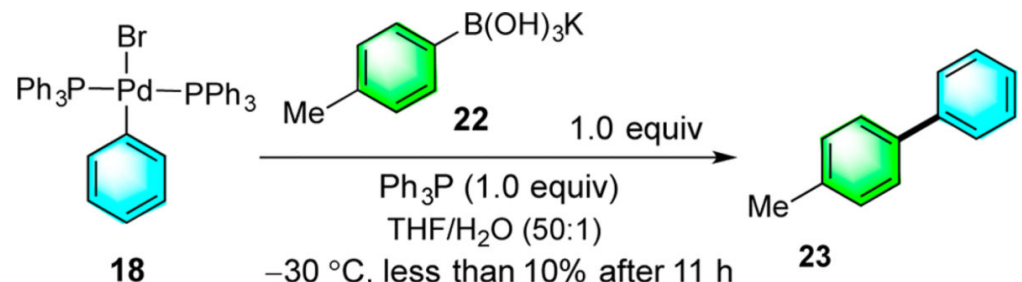

$18-30{ }^{\circ} \mathrm{C}$, less than $10 \%$ after $11 \mathrm{~h}$ $\mathrm{k}=1.7 \times 10^{-7} \mathrm{~s}^{-1}$

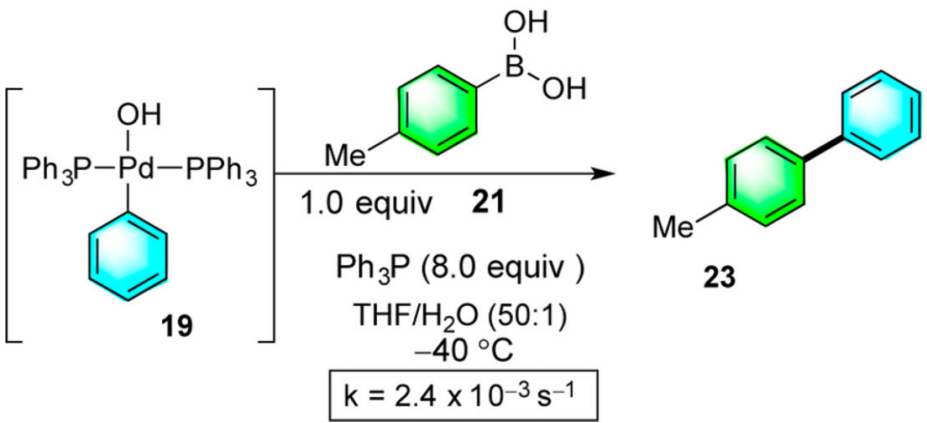

Scheme 5. 
<smiles>Cc1ccc(B(O)O)cc1</smiles><smiles>CCO[R6](=O)(=O)OCCO</smiles><smiles>[14CH3]C([14CH3])(O)[Pb]([14CH3])(O)c1ccccc1</smiles>

24

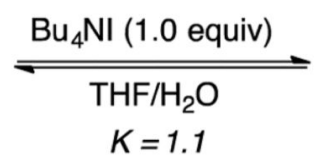

$K=1.1$

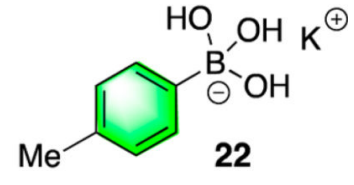

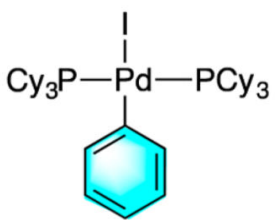

25

Scheme 6 .

\section{Scheme 6.}




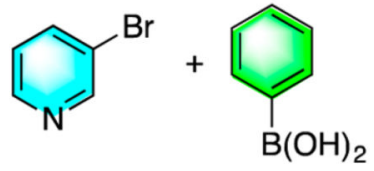

27

1
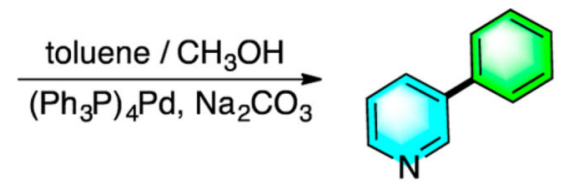

30

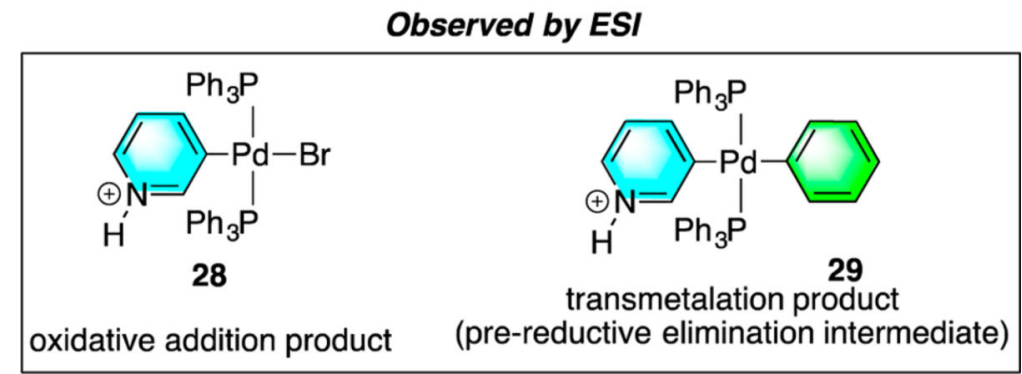

Scheme 7.

J Am Chem Soc. Author manuscript; available in PMC 2021 January 05. 

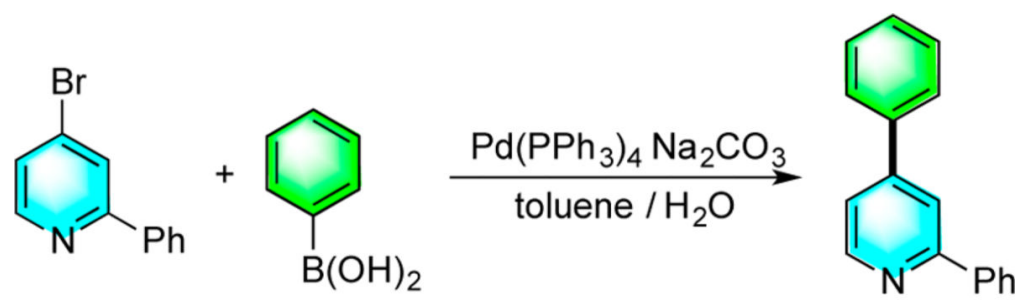

31

1

33

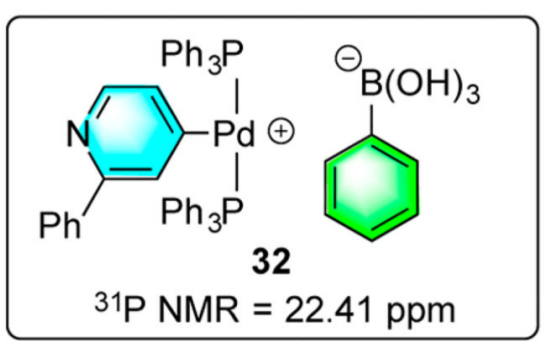

Scheme 8. 


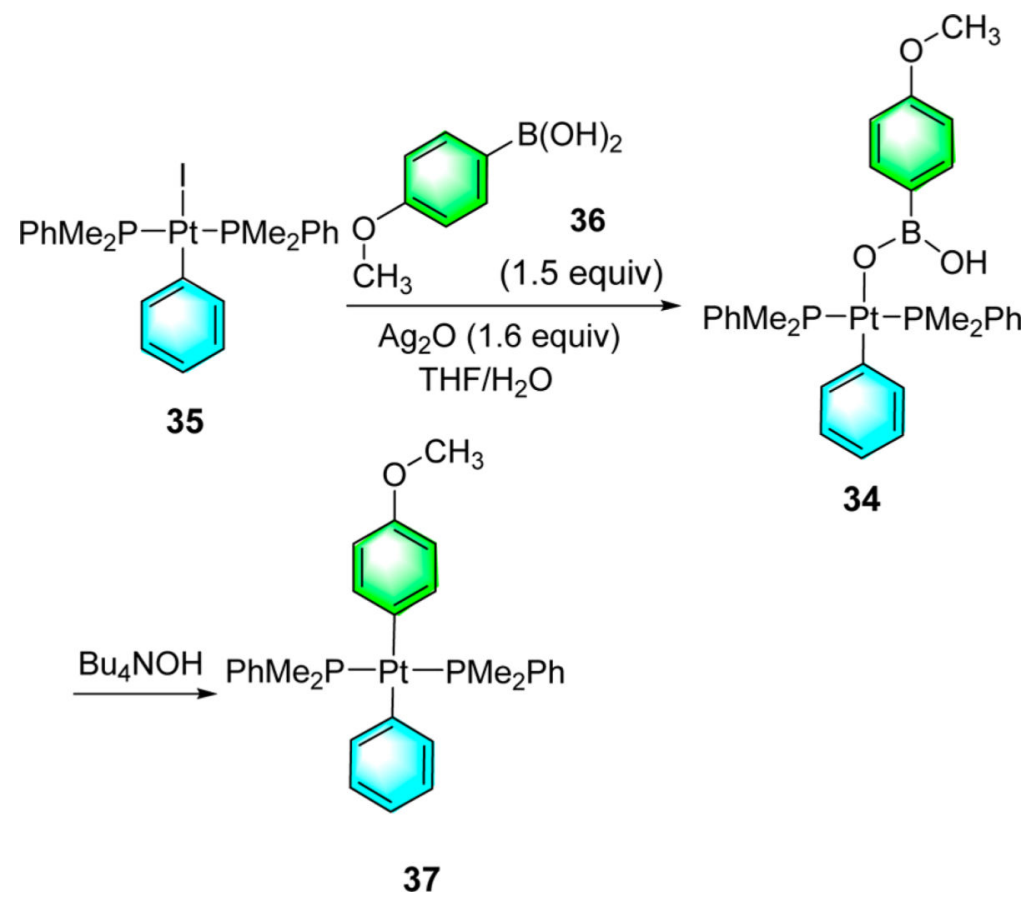

Scheme 9. 

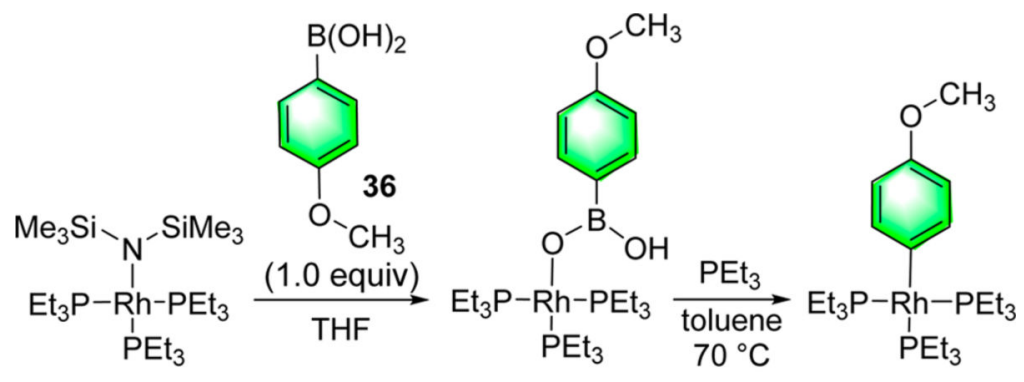

40

38

39

Scheme 10. 


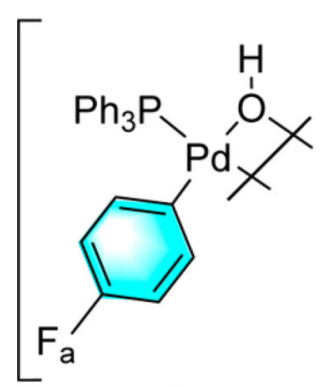

46
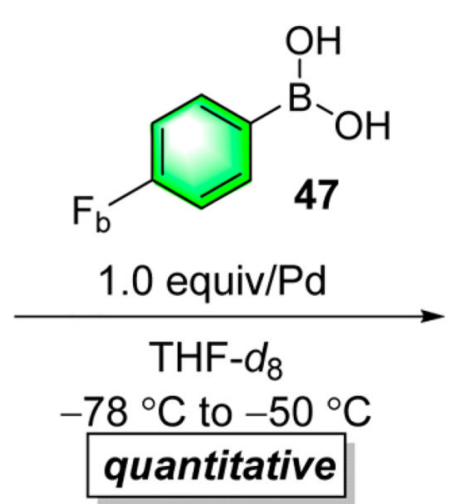

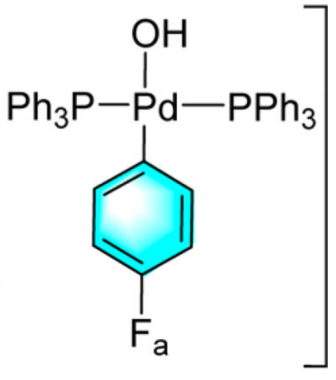

48

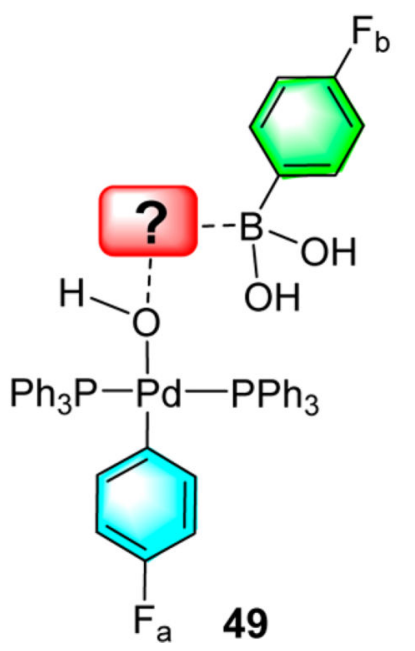

Scheme 11. 


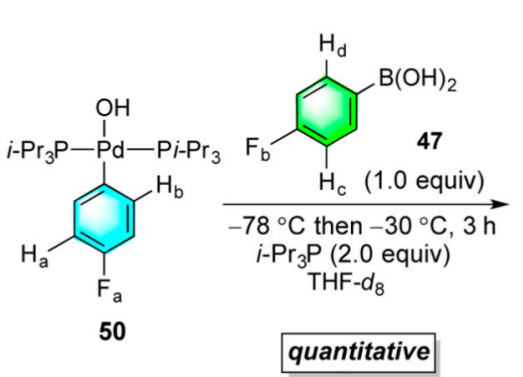

Scheme 12.
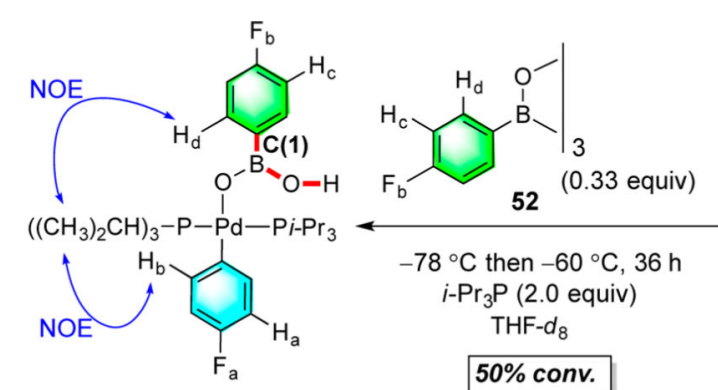

$-78^{\circ} \mathrm{C}$ then $-60^{\circ} \mathrm{C}, 36 \mathrm{~h}$ i- $\mathrm{Pr}_{3} \mathrm{P}$ (2.0 equiv) THF- $d_{8}$

$50 \%$ conv.

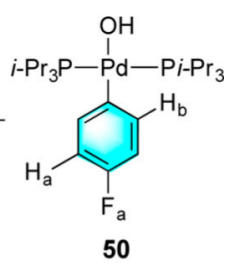

51 

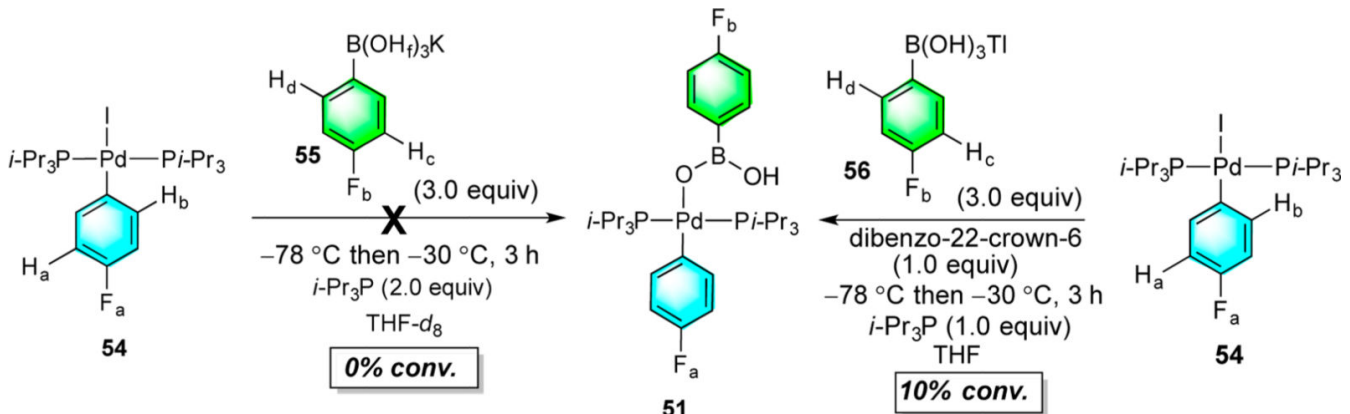

Scheme 13. 

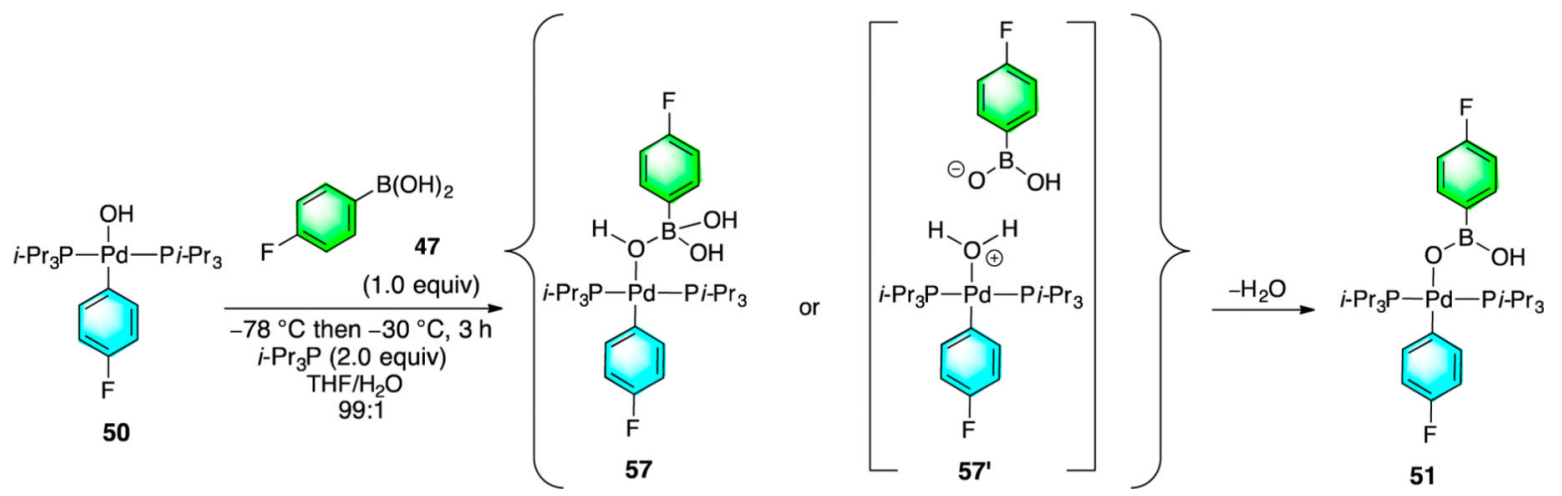

Scheme 14.

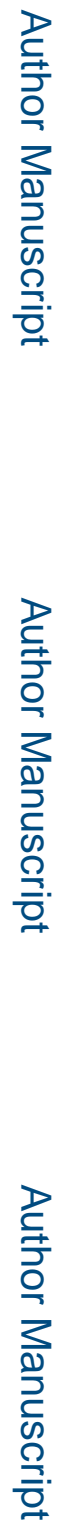

J Am Chem Soc. Author manuscript; available in PMC 2021 January 05. 


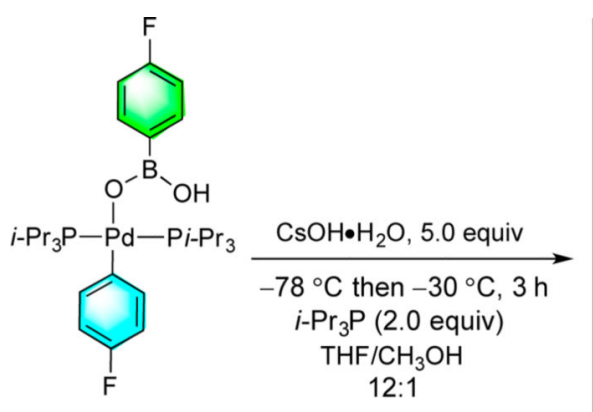

51

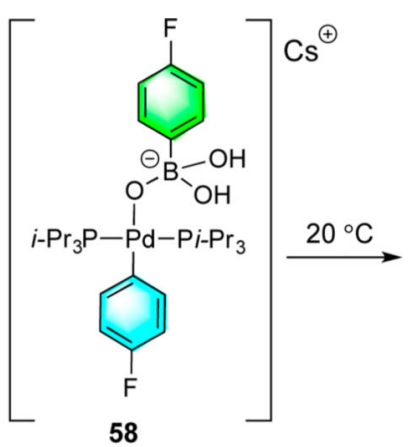

Not Observed

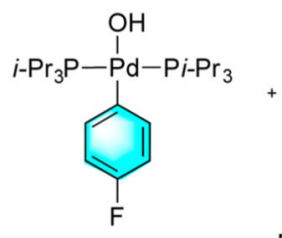

50

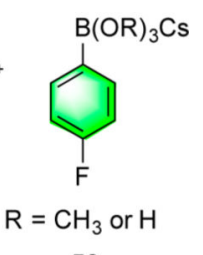

59

Scheme 15. 


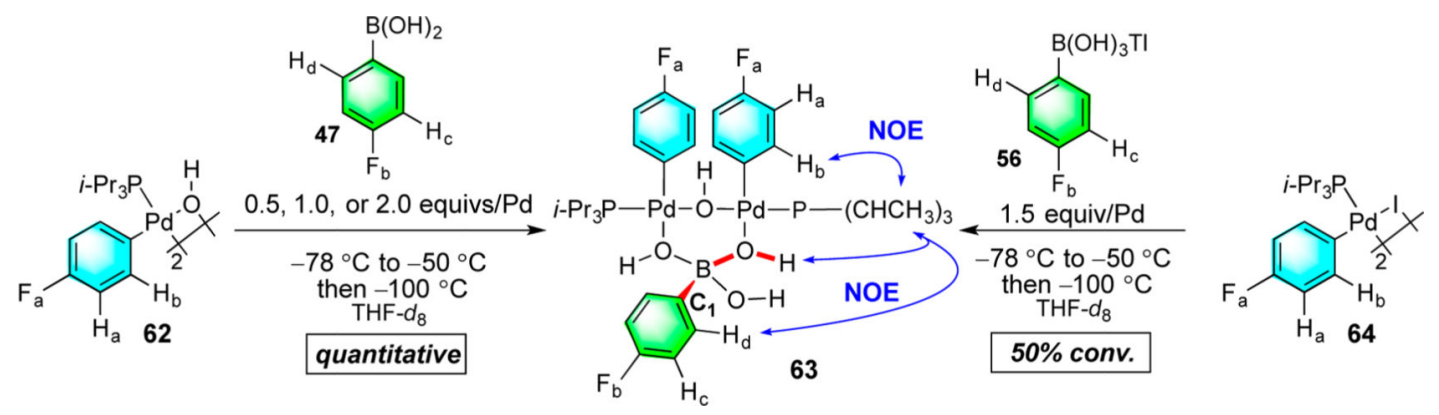

Scheme 16. 

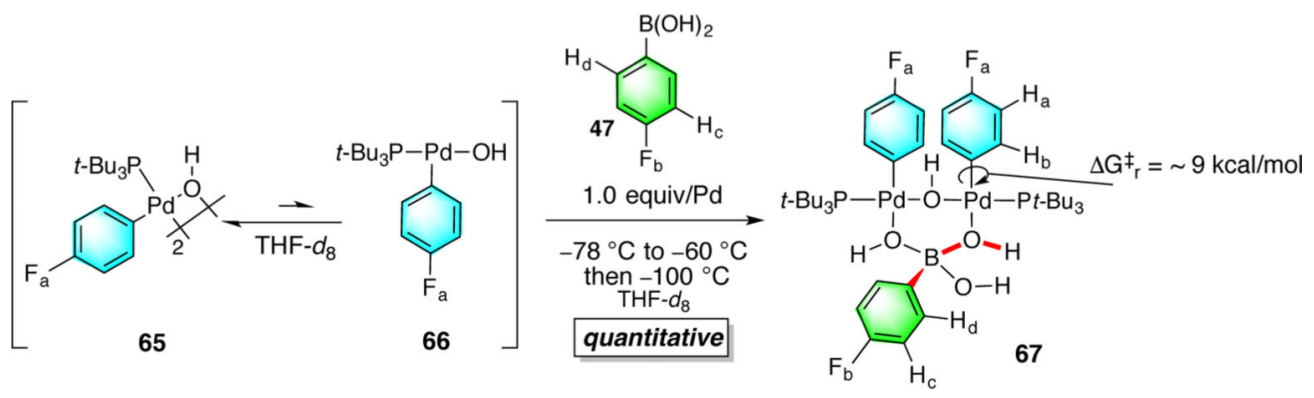

Scheme 17. 


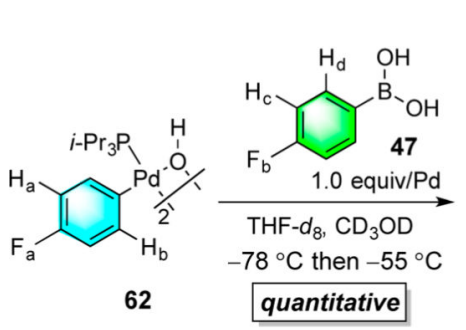

62

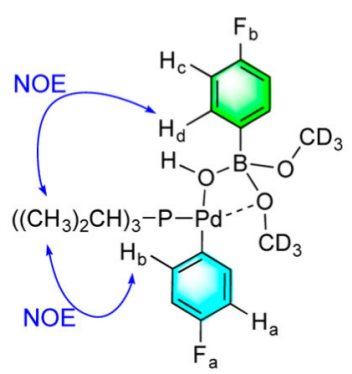

68

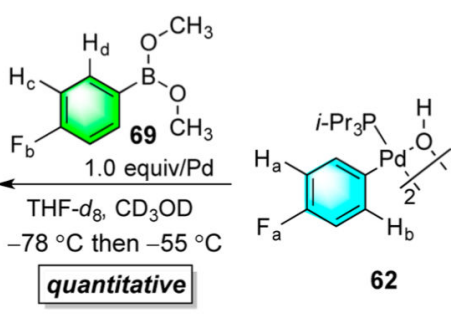

quantitative

Scheme 18. 


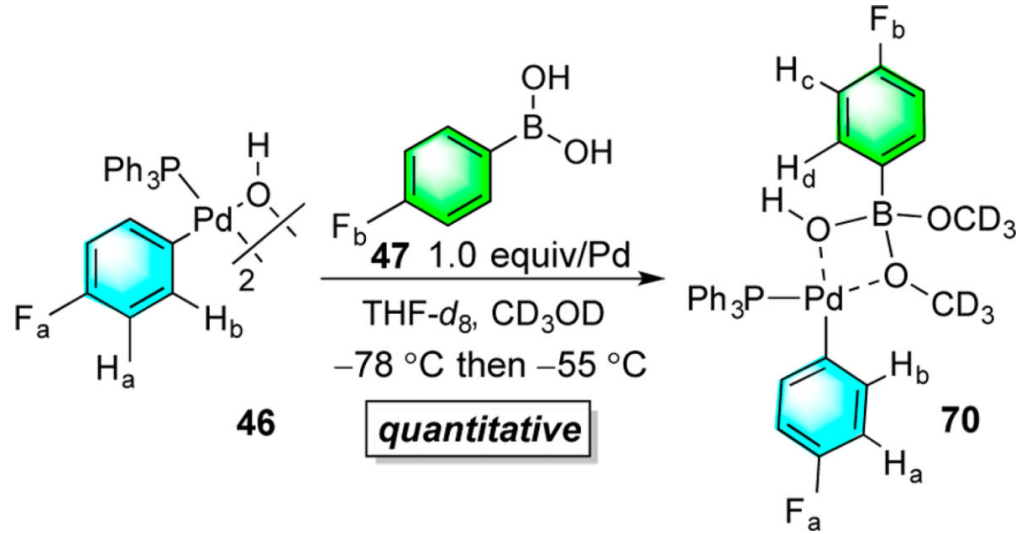

Scheme 19. 


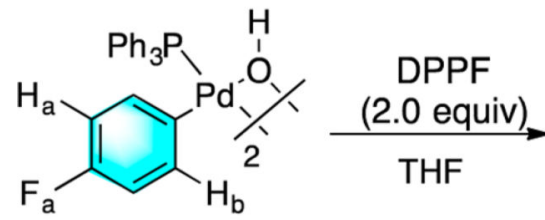

46

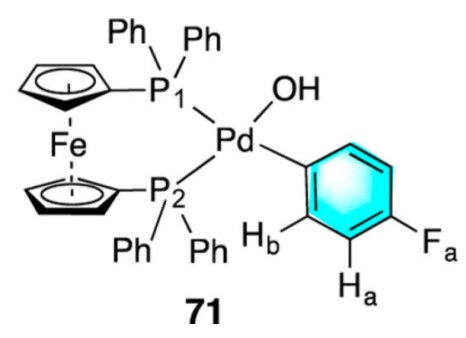

Scheme 20. 


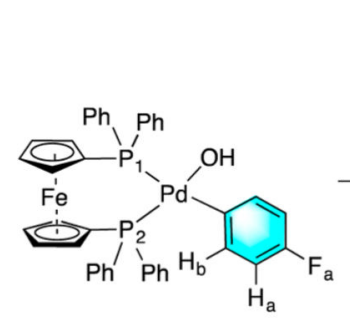

71

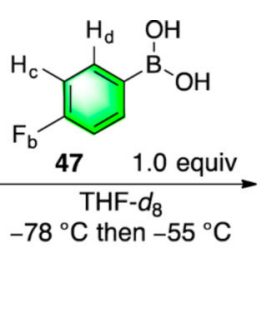

Scheme 21.

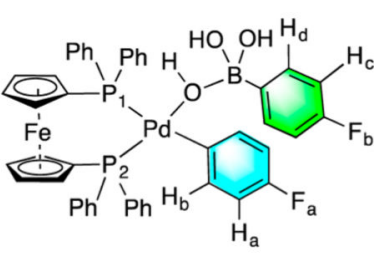

72 

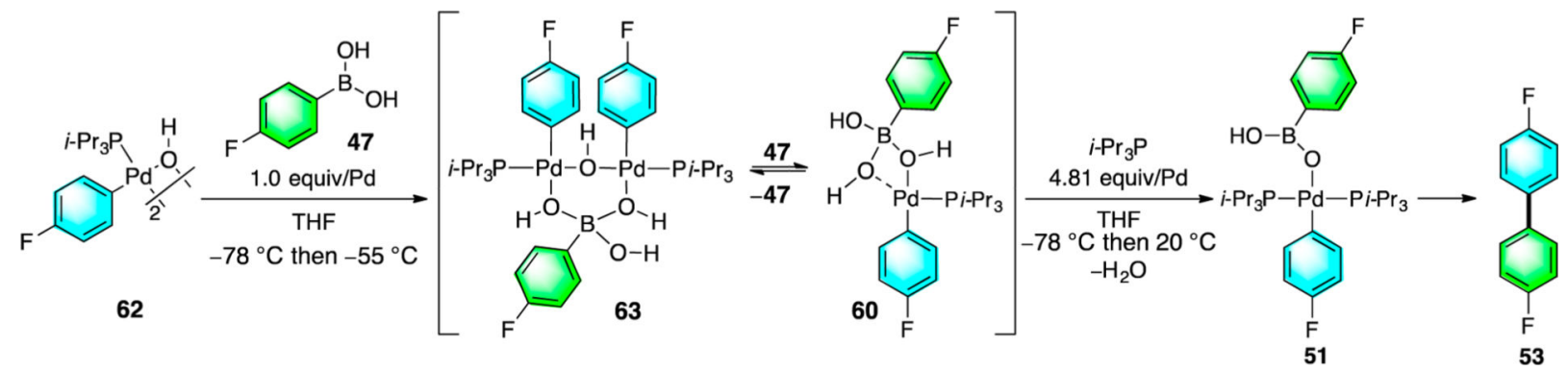

Scheme 22. 


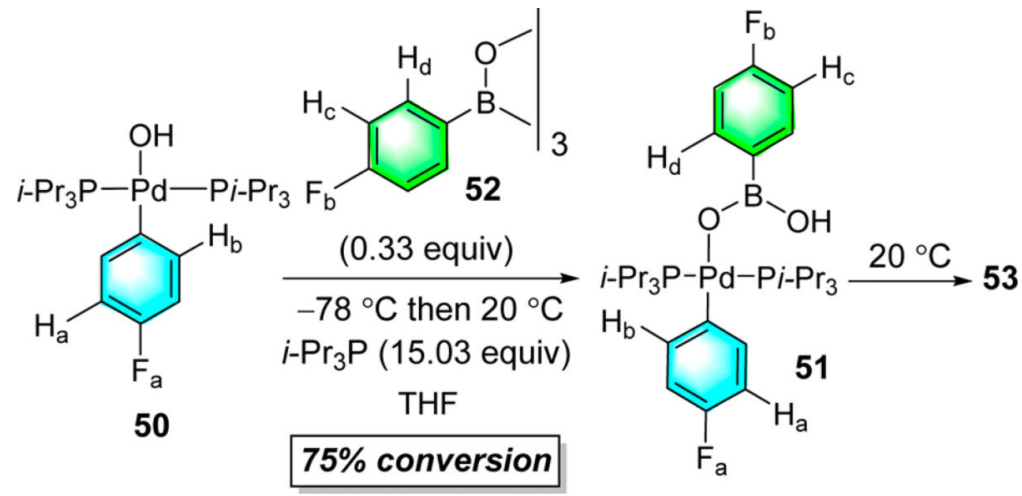

Scheme 23. 
Table 1.

Activation Parameters for the Transmetalation Step

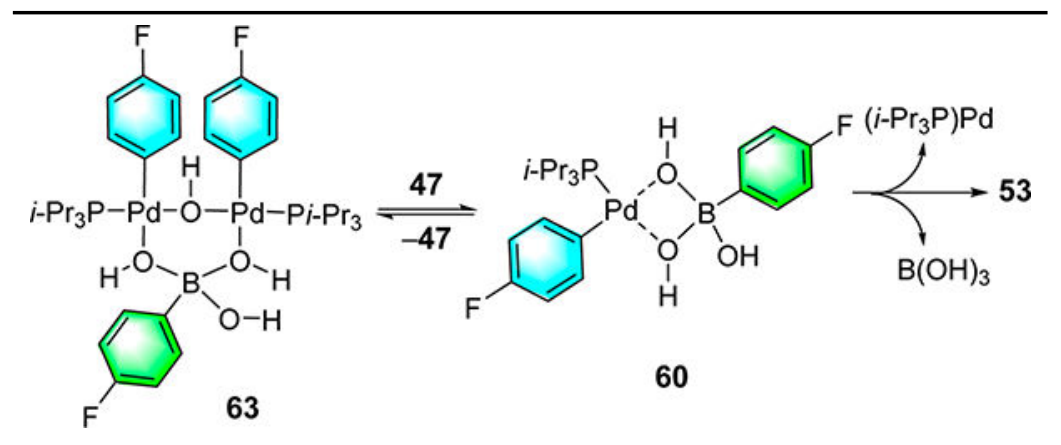

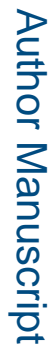

\begin{tabular}{|c|c|c|c|}
\hline entry & $\Delta G_{243.15}^{\ddagger}, \mathrm{kcal} / \mathrm{mol}$ & $\Delta H_{243.15}^{\ddagger}, \mathrm{kcal} / \mathrm{mol}$ & $\Delta S^{\dagger}, \mathrm{kcal} / \mathrm{mol} \cdot \mathrm{K}$ \\
\hline measured $^{a}$ & $17.7 \pm 1.1$ & $15.98 \pm 0.79$ & $-0.0069 \pm 0.0032$ \\
\hline calculated & 15.38 & 14.57 & -0.003 \\
\hline
\end{tabular}

${ }^{a}$ Average of triplicate runs. 
Table 2.

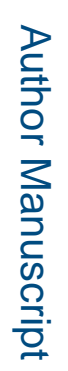

Effect of Phosphine Ligand on Rate ${ }^{a}$

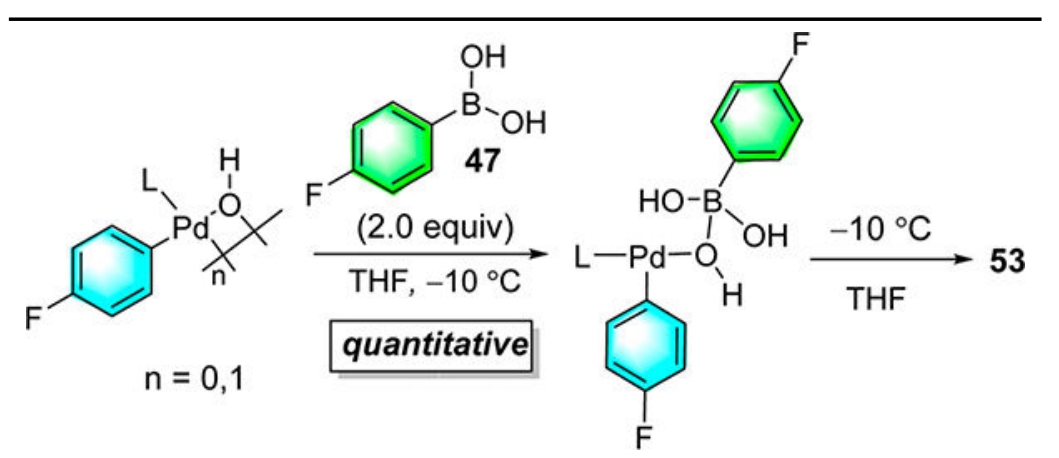

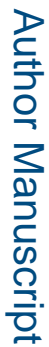

\begin{tabular}{cclll} 
entry & complex & \multicolumn{1}{c}{ ligand } & $\boldsymbol{k}^{\boldsymbol{a}} \mathbf{1 0}^{\mathbf{- 3}} \mathbf{s}^{\mathbf{- 1}}$ & $\boldsymbol{k}_{\text {rel }}$ \\
1 & $\mathbf{7 2}$ & $\mathrm{DPPF}$ & $2.75 \pm 0.05$ & 1.00 \\
2 & $\mathbf{6 0}$ & $i-\mathrm{Pr}_{3} \mathrm{P}$ & $8.09 \pm 0.86$ & 2.94 \\
3 & $\mathbf{7 3}$ & $\mathrm{Ph}_{3} \mathrm{P}$ & $9.95 \pm 0.71$ & 3.61 \\
\hline
\end{tabular}

${ }^{a}$ Average of triplicate runs. 
Table 3.

Rates of Cross-Coupling Product 53 Formation from $51^{a}$

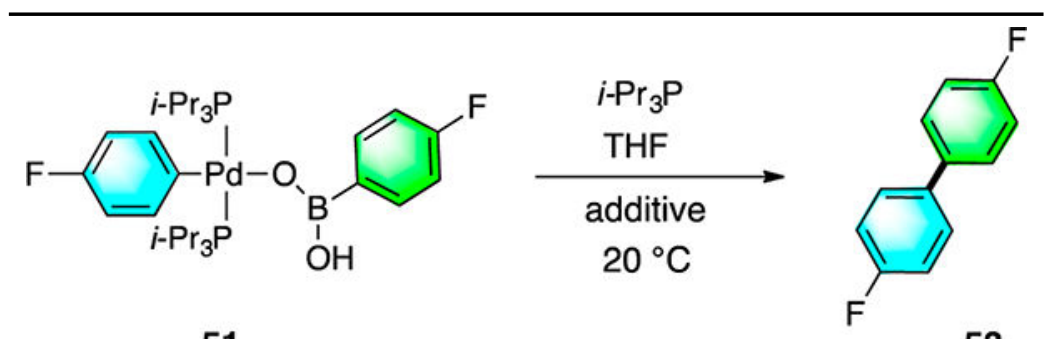

51

53

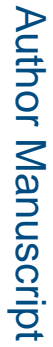

\begin{tabular}{cccc} 
entry & amount of $\boldsymbol{i}$-Pr $\mathbf{P} \mathbf{P}$, equiv & additive & rate, ${ }^{\boldsymbol{a}} \mathbf{1 0}^{\mathbf{- 3}} \mathbf{\mathbf { m M ~ s }} \mathbf{~}^{\mathbf{1}}$ \\
1 & 2.85 & - & $4.48 \pm 0.65$ \\
2 & 3.81 & - & $3.24 \pm 0.12$ \\
3 & 5.41 & - & $2.42 \pm 0.48$ \\
4 & 8.62 & - & $1.37 \pm 0.96$ \\
$5^{b}$ & 3.81 & $\left(i-\mathrm{Pr}_{3} \mathrm{P}\right)_{2} \mathrm{Pd}$ & $2.86 \pm 0.36$ \\
$6^{c}$ & 5.41 & $\mathrm{H}_{2} \mathrm{O}$ & $1.11 \pm 0.04$ \\
$7^{d}$ & 3.81 & - & $3.26 \pm 0.17$ \\
\hline
\end{tabular}

${ }^{a}$ Average of triplicate runs.

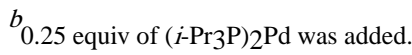

$c 10$ equiv of water was added.

${ }^{d}$ Complex 51 was formed by the addition of $i$-Pr3P to complex $\mathbf{7 3}$.

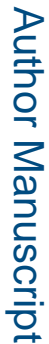

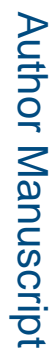

J Am Chem Soc. Author manuscript; available in PMC 2021 January 05. 